\title{
9th Medical Undergraduate Annual Scientific Research Meeting (MUASRM)
}

26 October 2017

\section{Universiti Kebangsaan Malaysia Medical Centre}




\title{
Patient Satisfaction on Patient-Controlled Analgesia
}

\author{
SENG BOON T, ELAMATHE M, AMIRUL EHSAN N, \\ KHAIRULAMIR Z \\ Department of Anaesthesiology and Intensive Care, Faculty of Medicine, Universiti \\ Kebangsaan Malaysia Medical Centre, Jalan Yaacob Latif, Bandar Tun Razak, 56000 \\ Cheras, Kuala Lumpur, Malaysia.
}

Background and aims: Patients' satisfaction on self-administered PatientControlled Analgesia (PCA) is an important indicator of quality of post-operative anaesthesia care. The study aimed to evaluate patients' satisfaction on PCA usage and the predictors that correlate with it.

Materials and methods: An observational study was conducted from May until August 2017. A validated questionnaire adopted from the Revised American Pain Society Patient Outcome Questionnaire 2010 was completed by 86 eligible postoperative patients.

Results: Mean age of respondents was $55.1 \pm 18.3$ years and mean duration on PCA pump was $2.4 \pm 1.1$ days. Median of patients' satisfaction with overall experience using PCA was 8 (out of 10 for most satisfied) $(\mathrm{IQR}=1.25)$. Median percentage of pain relief was $70 \%$ (IQR=40\%). There was a very strong positive correlation between satisfaction with overall experience using PCA and percentage of adequacy of pain relief $\left(r_{s}=0.762, p<0.001\right)$. On the other hand, significantly lower satisfaction level on overall experience was observed among patients who were unable to adequately control their pain compared to those who were able to adequately control their pain $(p=0.001)$. The easier the overall experience when using the PCA, the higher the percentage of pain relief achieved $\left(r_{s}=0.504, p<0.001\right)$. Those who were given adequate information regarding PCA pump were significantly more comfortable with using the PCA pump compared to those who were not $(p<0.05)$. Those who understood how to use PCA also felt more at ease in using the PCA pump compared to those who did not $(p<0.001)$. Mood and emotions such as anxiety, depression, frightened and helplessness had significantly positive correlation with patients' satisfaction level $(p<0.05)$.

Conclusion: Recommendations were made on providing adequate information regarding PCA to patients, in order to improve the effectiveness and patients' satisfaction with PCA so that better pain management can be achieved in the future.

Keywords: Pain management, Post-operative, Opioid 


\title{
Obstetrics Anal Sphincter Injury: A Preventable Injury?
}

\section{CHIN HENG T, THENMALAR S, MUHAMAD AMIN CA, SARAH \\ NABILA H, NORFAEZATUL FAZLINA N, BENG KWANG N, IXORA KAMISAN A, PEI SHAN L}

\begin{abstract}
Department of Obstetrics \& Gynaecology, Faculty of Medicine, Universiti Kebangsaan Malaysia Medical Centre, Jalan Yaacob Latif, Bandar Tun Razak, 56000 Cheras, Kuala Lumpur, Malaysia.
\end{abstract}

Background and aims: Obstetric anal sphincter injuries (OASIS) are not uncommon after vaginal delivery. To date, there is paucity of data with regard to prevalence of OASIS in Malaysia and its risk factors. The aim of this study was to determine the possible risk factors for OASIS.

Materials and methods: A case-controlled study was conducted in a teaching hospital from February to August 2016, retrospectively. A total of 343 women, consisting of 71 women who sustained OASIS (study group) and 272 women without (control group), were recruited in the analysis.

Results: The incidence of OASIS was $0.33 \%$ (ranged from 0.18 to 0.46 ) between 2012 and 2016. Significant risk factors for OASIS were duration of second stage of labour, instrumental delivery, delivery accoucher and birth weight $(p<0.05)$. However, maternal age, pre-delivery weight and body mass index, gestational age at delivery, induction of labour, oxytocin augmentation, epidural analgesia, duration of active phase and episiotomy were not associated with increased risk of OASIS ( $p>0.05)$.

Conclusion: Most risk factors related to OASIS were non-modifiable except duration of second stage; instrumental delivery and delivery accoucher were modifiable risk factors. Thus, early and accurate prediction of foetal weight, avoidance of instrumental delivery and trained delivery accoucher may all be implemented to reduce the risk of severe perineal tears such as OASIS.

Keywords: Episiotomy, Risk factors, Obstetric Labour, Complications, Pregnancy 


\title{
Carcinoembryonic Antigen Levels as an Independent Prognostic Marker for Colorectal Cancer
}

\author{
ZAHRAH S, AANANTHI M, HOCK JIE G, SITI NOR AB, RAZUL \\ IBNU ZMK, NUR AFDZILLAH AR, ZAIRUL AZWAN MA
}

\begin{abstract}
Department of Surgery, Faculty of Medicine, Universiti Kebangsaan Malaysia Medical Centre, Jalan Yaacob Latif, Bandar Tun Razak, 56000 Cheras, Kuala Lumpur, Malaysia.
\end{abstract}

Background and aims: Serum carcinoembryonic antigen (CEA) plays a significant role in prognosticating colorectal cancer. This study aimed to evaluate the prognostic values of pre-treatment and post-treatment CEA levels in colorectal cancer.

Materials and methods: This was a retrospective study that involved all patients diagnosed with histologically proven colonic adenocarcinoma in Universiti Kebangsaan Malaysia Medical Centre, from $1^{\text {st }}$ January 2007 until 31 ${ }^{\text {st }}$ December 2011. Only resectable rectal and left-sided tumours were taken into study. Patients were grouped based on pre-treatment and post-treatment CEA levels (elevated if CEA $>5.0 \mathrm{ng} / \mathrm{ml}$ and normal if CEA $<5.0 \mathrm{ng} / \mathrm{ml}$ ). Overall survival (OS), disease free survival (DFS), overall mortality (OM), disease specific mortality (DSM) and recurrence were compared between normal and elevated serum CEA (pre-treatment and post-treatment).

Results: A total of 81 patients were evaluated and of these, 39 patients had normal pre-treatment CEA levels and 42 had elevated pre-treatment CEA levels. Elevated pre-treatment CEA level was not significantly associated with OM and DSM ( $p>0.05)$. Post-treatment CEA levels of 98 patients were monitored, regardless of the measurement of pre-treatment CEA levels, and out of these, 56 were normal and 42 were elevated. Elevated post-treatment CEA levels were associated with 4.182 times and 4.080 times increased risk for OM $(\mathrm{HR}, 4.182: 95 \% \mathrm{Cl}, \mathrm{p}<0.05)$ and $\mathrm{DSM}(\mathrm{HR}$, 4.080: $95 \% \mathrm{Cl}, \mathrm{p}<0.05)$, respectively. Analysis of OS and DFS revealed, elevated pre-treatment CEA levels had worse prognosis across all Dukes' stages (both log rank $p<0.01)$.

Conclusion: The study showed that elevated pre-treatment CEA had poorer prognosis of colorectal cancer in term of OS and DFS, while elevated post-treatment CEA levels had significant risks for OM and DSM. Thus, it is recommended that routine CEA monitoring is used as standard investigation for colorectal cancer patients.

Keywords: CEA, Tumour Marker, Prognosis, Recurrence, Survival 


\title{
Olea Europaea Inhibits Epithelial-to-Mesenchymal Transition in Human Respiratory Epithelial Cells
}

\author{
HAFIZ NAE, TURKAMBIGAI J, ASYRAFI MAH, QISTINA A, NUR \\ FARHANA I, RABIATUL AR, RUSZYMAH BHI
}

\begin{abstract}
Department of Physiology, Faculty of Medicine, Universiti Kebangsaan Malaysia Medical Centre, Jalan Yaacob Latif, Bandar Tun Razak, 56000 Cheras, Kuala Lumpur, Malaysia.
\end{abstract}

Background and aims: Worsening air pollution and smoking leads to increase in lung related diseases. One of the molecular mechanisms involved in those diseases is Epithelial-to-Mesenchymal Transition (EMT) Type 2. Olive Extract (OE) has antiinflammatory effect, thus has high potential to prevent EMT type 2. The study aimed to investigate the effect of OE on EMT Type 2 in human Respiratory Epithelial Cells (RECs).

Materials and methods: RECs were obtained from nasal turbinate of consented patients $(n=7)$. RECs were divided into 4 groups: control group, $5 \mathrm{ng} / \mathrm{ml}$ of TGFß1 induced EMT, $0.05 \%$ of OE treated, and $5 \mathrm{ng} / \mathrm{ml}$ Transformation Growth Factor Beta-1 (TGFß-1) + 0.05\% OE treated. The effects of OE to RECs were evaluated by observing RECs' growth kinetics and morphology. Total percentage of vimentin expression was quantitated from day 1 until day 3 using immunocytochemistry analysis. Data collected was analysed using Prism 7.

Results: REC $(0.832 \pm 0.002)$ had circular shape, which was similar to $\mathrm{OE}(0.865 \pm 0.002)$ and OE+TGFß-1 $(0.887 \pm 0.002)$ treated groups. Only TGFß-1 group was significantly elongated $(0.717 \pm 0.005)$ compared to them. There was no significant difference in total cell number and proliferation rate between the RECs and all groups from day 0 to day 3 ( $p>0.05)$. There was an increasing trend observed in the total cell number of RECs and OE group from day 0 to day 3. However, no difference was observed in total cell number of TGFß-1 and OE+TGFß-1 from day 0 to day 3. Percentage of vimentin expression showed significant reduction in TGFß-1+OE group, compared to TGFß-1 group $(\mathrm{p}<0.05)$. Expression of vimentin showed reduction trend in $\mathrm{OE}$ group compared to the other group.

Conclusion: OE did not promote proliferation of REC. However, OE demonstrated a trend of inhibiting TGFß-1 induced EMT. Therefore, OE has a potential to modulate wound healing in diseases involving respiratory epithelium.

Keywords: Olive, Vimentin, Wound Healing, Epithelial-to-Mesenchymal Transition 


\title{
Factors Affecting Adherence to Glaucoma Therapy: The Universiti Kebangsaan Malaysia Medical Centre Experience
}

\author{
SWEE THIAN T, BAANU T, IZIANI SAZLIA M, NURUL MURNI S, \\ JEMAIMA CH, RONA ASNIDA N \\ Department of Ophthalmology, Faculty of Medicine, Universiti Kebangsaan Malaysia \\ Medical Centre, Jalan Yaacob Latif, Bandar Tun Razak, 56000 Cheras, Kuala Lumpur, \\ Malaysia.
}

Background and aims: Glaucoma is one of the leading causes of blindness worldwide. It is becoming an important global public health concern with the proportion of patients burdened with this sight-threatening disease ever rising due to the rapidly increasing aging population. Due to the chronicity of the disease, treatment is usually life-long. Since the majority of glaucoma patients are managed initially with medical therapy, sustained and consistent adherence is critical for preventing disease progression. This study aimed to determine the factors affecting adherence to medical therapy in glaucoma patients.

Materials and methods: A cross-sectional study involving 143 glaucoma and ocular hypertensive patients was conducted in the Ophthalmology Clinic, Universiti Kebangsaan Malaysia Medical Centre from 15 September till 21 September 2017. Patients were selected by convenience sampling and they completed questionnaires via a face-to-face interview with the investigators. Socio-demographic data, information pertaining to the disease, treatment-related and individual-related problems were collected. The adherence to glaucoma therapy was evaluated by utilizing the Morisky Medication Adherence Scale (MMAS).

Results: A total of 54 patients (37.8\%) were completely adherent to their prescribed glaucoma therapy. Factors found to be significantly affecting adherence were ethnicity $(p=0.008)$, patient-related issues such as forgetting the medications $(p=0.00)$ and the belief in uselessness of the medications $(p=0.04)$.

Conclusion: Despite glaucoma being a potentially blinding disease, patients' adherence to medical therapy was still low. Adherence to glaucoma therapy was multifactorial, and these factors should be examined further. Appropriate patient education is crucial in improving adherence.

Keywords: Medications, Compliance, Multifactorial 


\title{
Preliminary Study on the Prevalance of Waterborne Parasite in Tasik Permaisuri, Cheras
}

\author{
UUN XIAN T, MEESHALINY M, SITI WAHIDAH Z, SYUBAI'AH O, \\ MOHD AMINUDDIN H, AZLIN M \\ Department of Parasitology \& Medical Entomology, Faculty of Medicine, Universiti \\ Kebangsaan Malaysia Medical Centre, Jalan Yaacob Latif, Bandar Tun Razak, 56000 \\ Cheras, Kuala Lumpur, Malaysia.
}

Background and aims: Waterborne parasites cause serious diseases in humans worldwide. Recreational lakes and rivers have been known to be important sources of infection because transmission may occur due to exposure to water-related activities in humans. This is the first study conducted to reveal the occurrence of common waterborne parasites in a popular urban lake, Tasik Permaisuri, Cheras.

Materials and methods: A total of 64 samples from eight different sites, each consisting of six litres were taken in this cross sectional study. Filtration of water samples were carried out using flatbed nitrocellulose membrane filtration system (0.45 $\mu \mathrm{m}$ pore size, $142 \mathrm{~mm}$ diameter, millipore). The sediments were examined using conventional methods such as direct smear, concentration techniques and permanent staining methods. Slides were viewed under microscope attached to image analyser (Model-CX40 from Olympus). The results were confirmed by two trained technicians.

Results: The prevalence of waterborne parasites detected was $31.25 \%$, in which 20 out of 64 samples were positive. Most prevalent species were free living amoeba $32 / 64(50 \%)$, Entamoeba complex 16 out of $64(25 \%)$, Hookworm 7 out of 64 $(10.9 \%)$, Ascaris spp. 4 out of $64(6.3 \%)$ and Trichuris spp. 3 out of $64(4.7 \%)$, and Giardia spp. 2 out of 64 (3.1\%). Several Schistosome like ova were found on surface samples, in which the mean temperature was $30.76^{\circ} \mathrm{C}$, mean $\mathrm{pH}$ was 6.84 , mean turbidity was 10.36 Nephelometric Turbidity Unit (NTU) and mean dissolved oxygen was $20.41 \mathrm{mg} / \mathrm{ml}$.

Conclusion: In contrast to previous researches in urban lakes, this study yielded lower prevalence of parasites which was possibly due to the conventional methods used. The parasites were also found mostly on surface water. However, in this study the morphology of parasites found was clearly visualised thus it is safe to conclude that Tasik Permaisuri, Cheras harbours waterborne parasites.

Keywords: Lake, Infection, Hookworm, Urban 


\title{
Prevalence of Chronic Upper Extremities Musculoskeletal Pain among Healthcare Workers and its Associated Factors in Universiti Kebangsaan Malaysia Medical Centre
}

\author{
AMNAH 'ALIA A, ABIGAIL BATHSHEBA D, NORSHAZWANI AZ, \\ KHAI SHEN G, SUHAYL AZMIN R,_HANIZAH MY \\ Department of Public Health, Faculty of Medicine, Universiti Kebangsaan Malaysia \\ Medical Centre, Jalan Yaacob Latif, Bandar Tun Razak, 56000 Cheras, Kuala Lumpur, \\ Malaysia.
}

Background and aims: Healthcare workers (HCWs) are greatly exposed to work related musculoskeletal disorders (MSDs). Lack of awareness on MSDs, especially upper extremities musculoskeletal pain (UEMSP), resulted in work disturbance and low productivity. Therefore, this study aimed to determine the prevalence of chronic UEMSP and its associated factors among HCWs. Besides that, this study also aimed to determine the percentage of common MSDs among those having chronic UEMSP.

Materials and methods: A cross-sectional study was conducted among 410 HCWs, comprising staff nurses and healthcare assistants in Universiti Kebangsaan Malaysia Medical Centre. The respondents were recruited through stratified random sampling. Data was collected via self-administered questionnaire and the MSDs were detected by physical examination following the Criteria Document for Evaluating the Work-Relatedness of Upper-Extremity Musculoskeletal Disorders. Logistic regression was used to identify factors associated with chronic UEMSP.

Results: Prevalence of chronic UEMSP among HCWs was 30.5\%. The percentage of those suffered from work disturbances was $32 \%$, while $29.6 \%$ were found to have at least one of the four common MSDs of upper limb; carpal tunnel syndrome $(12.2 \%)$, radiating neck pain $(9.8 \%)$, rotator cuff syndrome $(9.8 \%)$ and epicondylitis (5.6\%). Comorbidities [AOR=2.34 (95\% Cl: 1.288-4.240)] and high stress level $[A O R=2.16$ (95\% Cl: 1.348-3.467)] were associated with chronic UEMSP among HCWs. However, HCWs who lifted and changed position of the patients had lower risk of getting chronic UEMSP [AOR=0.597 (95\% Cl: 0.363-0.982)].

Conclusion: The prevalence of chronic UEMSP among HCWs was high. Thus, early intervention to prevent worsening of chronic UEMSP is recommended to improve life quality.

Keywords: Upper limb, Nurses, Shoulder, Wrist 


\title{
Evaluation of Treatment Patterns and Outcomes in Patients with Acute Myeloid Leukaemia: A Retrospective Analysis
}

\author{
GHAYATHIRI P' ${ }^{1}$ BILLY CCN ${ }^{1}$, ABDUL RAUF $Y^{1}$, NURUL \\ HAKIMAH A ${ }^{1}$, FAREHAN MI ${ }^{1}$, HAYATI Y ${ }^{1}$, SYED ZULKIFLI SZ ${ }^{2}$, \\ TUMIAN NR ${ }^{1}$
}

\begin{abstract}
${ }^{1}$ Department of Medicine, ${ }^{2}$ Department of Paediatrics, Faculty of Medicine, Universiti Kebangsaan Malaysia Medical Centre, Jalan Yaacob Latif, Bandar Tun Razak, 56000

Cheras, Kuala Lumpur, Malaysia.
\end{abstract}

Background and aims: There is limited published data on clinical characteristics, treatment responses and survival outcomes in adult patients with acute myeloid leukaemia (AML) in Malaysia. The aim of the present analysis was to determine the treatment patterns and outcomes in patients with AML in Universiti Kebangsaan Malaysia Medical Centre (UKMMC).

Materials and methods: In this retrospective observational study, 80 patients $\geq 13$ years of age and diagnosed with AML who were diagnosed between January 2000 and June 2017, were included. Demographic data, clinical parameters and treatment of these patients were retrieved from patients' files and hospital electronic data system, and critically analysed. Overall survival (OS) statistics were computed using Kaplan-Meier method.

Results: The patients were predominantly Malay women (41.3\%) and median age at diagnosis was 50.2 years (range, 13.7-79.8). Sixty-eight patients (85\%) received standard induction chemotherapy, $9(11.3 \%)$ received palliative treatment/ best supportive care (BSC) while $3(3.8 \%)$ refused treatment. Among those who received standard induction chemotherapy, $68.2 \%$ achieved complete remission. Median OS from diagnosis for all patients was 25.9 months $(95 \% \mathrm{Cl}$ : $0.25-51.53)$. The 2-, 5 - and 10 -year survival rates, were $46 \%, 40 \%$ and $34 \%$, respectively. Median OS of the patients who received standard induction chemotherapy, palliative treatment/ BSC and those who refused treatment was 35.4 months (95\% Cl: 0.00-74.78), 8.9 months (95\% Cl: $3.70-14.04)$ and 4 months (95\% Cl: $0.00-8.41)$, respectively, $[\mathrm{p}=0.17]$.

Conclusions: Our study showed that AML in our centre was predominantly found in Malay women. The complete remission rate was not inferior to studies in Western countries. Although not statistically significant, patients who received palliative care/BSC had slightly longer OS compared to those who refused treatment. This may translate to a better quality of life in this group of patients. However, this needs to be ascertained in a larger cohort of patients involving a multicentre study.

Keywords: AcuteMyeloid Leukaemia, Survival, Complete Remission, Chemotherapy 


\title{
Prevalence of Online Health Information Seeking Among Diabetics, Type of Information Sought and its Association with Diabetes Self-Management
}

\author{
THENMOLLE A ${ }^{1}$, MOHAMAD SALEHUDDIN MS ${ }^{1}$, NATASHA \\ PAYA J', BARATHAN $M^{1}$, NUR IZZATI AS ${ }^{1}$, LEELAVATHI ${ }^{1}{ }^{1}$, TEH \\ ROHAILA J', WEI WEN C ${ }^{2}$
}

${ }^{1}$ Department of Family Medicine, Faculty of Medicine, Universiti Kebangsaan Malaysia Medical Centre, Jalan Yaacob Latif, Bandar Tun Razak, 56000 Cheras, Kuala Lumpur, Malaysia.

${ }^{2}$ Faculty of Pharmacy, Universiti Kebangsaan Malaysia.

Background and aims: Diabetes is a lifelong condition, hence disease selfmanagement is vital. The internet offers an amazing wealth of health information which may influence disease self-management. The study aimed to determine the prevalence of online health information seeking among diabetics and its associated factors.

Materials and methods: This was a cross-sectional study among 380 diabetics at Universiti Kebangsaan Malaysia Medical Centre. The online health information seeking for diabetes was assessed using a questionnaire developed from literature search and expert panel review. Diabetes Self-Management was assessed using the Diabetes Self-Management Questionnaire (DSMQ) where a score 6 reflected optimal diabetes self-control.

Results: The prevalence of online health information seeking among diabetics was $38.4 \%(n=146)$. Common information sought included diabetic treatment $(82.9 \%$, $\mathrm{n}=146)$, lifestyle modification $(77.4 \%, \mathrm{n}=146)$ and diabetes prevention $(67.3 \%$, $\mathrm{n}=146)$. Frequency of seeking online information was two to three times in six months $(37 \%, n=54)$. A large majority $(93.1 \%, n=136)$ found the online diabetes information useful. Doctors $(94.2 \% \mathrm{n}=358$,$) and printed reading materials (65.3 \%$ $\mathrm{n}=248$ ) were identified as the most common source of information obtained for diabetes. Lower median age (59 years, $\mathrm{QQR}=11)$, having a diabetic family member $(p=0.04, C O R=1.188 ; 95 \% \mathrm{Cl}=0.507-2.783)$, tertiary education $(\mathrm{p}<0.001$, $\mathrm{COR}=6.037 ; 95 \% \mathrm{Cl}=3.809-9.568)$ and those who were employed (COR=3.880; $95 \% \mathrm{Cl}=1.627-9.254, \mathrm{p}<0.001)$ had a significant association with seeking online health information. However, there was no significant association between online health information seeking and diabetes self-management (COR=1.702; 95\% $\mathrm{Cl}=0.768,3.774 \mathrm{p}=0.666)$.

Conclusion: This study showed that the prevalence of online health information 
seeking among diabetics was at an acceptable level. However, it was not associated with optimal diabetic self-management. Doctors and printed information remain as popular sources of information and hence should be maintained.

Keywords: Internet, Chronic Disease, Self Care, Behaviour. 


\title{
Evaluation of Psychological Video Intervention on Magnetic Resonance Imaging Outcomes: A Preliminary Study
}

\author{
FARAH IZZATI R' ${ }^{1}$ DHARSYINI M', CYRILL BOJIE B', \\ NORSHAFIKA NADIRA TAZ ${ }^{1}$, RIZUANA IH ${ }^{1}$, MAHADIR A ${ }^{2}$ \\ ${ }^{1}$ Department of Radiology, ${ }^{2}$ Health Psychology Program, Faculty of Medicine, Universiti \\ Kebangsaan Malaysia Medical Centre, Jalan Yaacob Latif, Bandar Tun Razak, 56000 \\ Cheras, Kuala Lumpur, Malaysia.
}

Background and aims: Magnetic Resonance Imaging (MRI) is a non-invasive sensitive imaging modality. During image processing, excessive motion may impair image quality and create motion artefacts as compared to other imaging modalities. The main aim of this study was to evaluate the effectiveness of psychological video intervention on MRI scan outcome. There were no similar studies done previously in Malaysia.

Materials and methods: A quasi-experimental study was conducted in Universiti Kebangsaan Malaysia Medical Centre (UKMMC) for four months, where 116 patients underwent MRI procedure. A video regarding MRI preparation and relaxation technique was given to the intervention group before the procedure. MRI-Self Efficacy Questionnaire (MRI-SEQ) was given to both intervention group $(n=58)$ and control group $(n=58)$ prior to MRI procedure. Radiographers, blinded to the group allocation, rated MRI scan for motion artefact and assessed scan completion.

Result: Psychological intervention did not influence scan completion, where $100 \%$ of all patients in both groups successfully completed their scan. However, there was significant difference between control and intervention group in respect to motion artefact $(p<0.001)$. There was significant difference in MRI-SEQ scores for control group $(M=60.05)$ and intervention group $(M=67.68)$ with $p<0.001$. Furthermore, when patient's MRI-SEQ score was raised by 1 unit, the odd ratio was 0.8 times more likely to have no motion artefacts $(p<0.001)$.

Conclusion: Psychological video intervention was able to improve patient selfefficacy, which in turn improved image quality. Thus, this intervention is highly recommended for UKMMC. It also has the potential to be beneficial to our nation.

Keywords: Claustrophobia, Artefacts, Relaxation Techniques, Scan 


\title{
Factors Associated with Female Pelvic Organ Prolapse Recurrence After a Reconstructive Surgery
}

\author{
MOHD ISKANDAR MZ, NUR AZLAN AR, YUAN ZHANG L, SITI \\ NUR AM, CHARMAINE SYALINI D, VANNESE PJW, YULIANTY A, \\ IXORA KA
}

Department of Obstetrics and Gynaecology, Faculty of Medicine, Universiti Kebangsaan Malaysia Medical Centre, Jalan Yaacob Latif, Bandar Tun Razak, 56000 Cheras, Kuala Lumpur, Malaysia.

Background and aims: Recurrence after reconstructive surgery for pelvic organ prolapse (POP) is a known complication. However, such information involving Asians is still lacking. This study aimed to determine the factors associated with POP recurrence after a reconstructive surgery in Asians.

Materials and methods: This was a retrospective observational study involving 72 women who had prolapse surgery in Universiti Kebangsaan Malaysia Medical Centre from 2006-2017. Patients were identified from the operating theatre database. All data were obtained from patients' medical records. Primary outcome measures were subjective and objective POP recurrence. Categorical and continuous explanatory variables were analysed using the Fishers exact and binary logistic regression test, respectively.

Results: Of the 72 women who had surgery, 11 were excluded due to missing data, leaving 61 for analysis. Majority were Malays and Chinese, 39\% ( $n=24)$, each. Mean age at surgery was 63.7 (Standard deviation (SD) 7.7) years with mean Body Mass Index (BMI) of $24.4(\mathrm{SD} 4.4) \mathrm{kg} / \mathrm{m}^{2}$. Median parity was 4 (Interquartile range $3-5)$. Pre-operatively, $88.5 \%(n=54)$ were symptomatic and $83.6 \%$ had significant FPOP of Grade/Stage 2. At a mean 23.3 (SD24.3) months post-operatively, 5\% $(n=3)$ and $31 \%(n=19)$ had subjective and objective recurrence, respectively. Age at surgery and $\mathrm{BMI}$ showed a trend towards significant association with objective POP recurrence Odds ratio (OR) 0.9 (95\% Confidence interval $(\mathrm{Cl}) 0.9-1.0) ; p=0.06$ and OR $1.2(95 \% \mathrm{Cl} 1.0-1.3) ; \mathrm{p}=0.09$, respectively. Perioperative complications are associated with subjective POP recurrence $(p=0.01)$. Age at follow-up, operative duration, level of surgeon, ethnicity and POP stage pre-operatively showed no significant difference in the recurrence rate $(p=0.1-0.9)$.

Conclusions: Perioperative complications were associated with subjective POP recurrence. $\mathrm{BMI}$ and age at surgery showed a trend towards association with FPOP recurrence. Higher pre-operative POP stage is not associated with recurrence.

Keywords: Prolapse, Recurrence, Vaginal Hysterectomy 


\title{
The Effect of Palm Tocotrienol on Osteoblast and Osteoclast Populations in Glucocorticoid-Induced Osteoporotic Rat
}

\author{
REINUKAA P, AZIZI Z, EDWIN HMO, NURUL HUSNA AB, NOR \\ AZIMAH Z, ELVY SUHANA MR, MOHAMAD FAIRUZ Y. \\ Department of Anatomy, Faculty of Medicine, Universiti Kebangsaan Malaysia Medical \\ Centre, Jalan Yaacob Latif, Bandar Tun Razak, 56000 Cheras, Kuala Lumpur, Malaysia.
}

Background and aims: Balanced interaction between osteoblast and osteoclast plays a major role in maintaining bone strength and structural integrity. Tocotrienol, a palm derivative with potent antioxidant properties showed an anti-osteoporotic effect but little is known about its mechanism of action. Hence, this research was conducted to determine the effects of palm tocotrienol on the glucocorticoidinduced osteoporotic bones by examining the numbers of osteoblast and osteoclast cells.

Materials and methods: The study involved 40 male Sprague-Dawley rats weighing 250-300g which were randomly divided into the baseline, shamoperated, adrenalectomized with dexamethasone (adrenalectomized control), and adrenalectomized with dexamethasone supplemented with either palm tocotrienol or alpha-tocopherol orally, for two months. Either tibia or femur was harvested for histochemical study using Tartrate-Resistant Acid Phosphate (TRAP) and Alkaline Phosphatase (ALP) staining. A double-blind experiment was performed to calculate the number of total cells (osteoblasts and osteoclast) with intact nuclei within five fields of view.

Results: The population of osteoclast in adrenalectomized control rat group showed an increase of $10 \%$ compared to the baseline. However, when palm tocotrienol was supplemented, the osteoclast population showed a significant decrease $(p<0.05)$ compared to the adrenalectomized control group. In contrast, osteoblast population showed a drastic decrease in adrenalectomized control rat compared to baseline group by $40 \%(p<0.05)$. However, when treated with palm tocotrienol, the osteoblast population increased significantly $(p<0.05)$ compared to adrenalectomized control group.

Conclusion: Our results showed the positive effects of palm tocotrienol, which revert the dynamics of osteoblast and osteoblast population in the osteoporotic bone to its pre-osteoporotic levels. Supplements of tocotrienol in daily diet may be beneficial in preventing glucocorticoid-induced osteoporosis.

Keywords: Antioxidant, Osteoporosis, Bone, Vitamin E 


\title{
Role of Anion Gap and Base Excess as Tools of Unmeasured Anions and Prediction of Hyperlactataemia and Mortality in Intensive Care Unit
}

\author{
NURSYAZWANI AINAA R, SITI FATIMAH A, NUR AZHANI MA, \\ SHAAMINI M, YONG HAO L, ALIZA MY, SHEREEN SPT, SAW \\ KIAN C
}

Department of Anaesthesiology and Intensive Care, Faculty of Medicine, Universiti Kebangsaan Malaysia Medical Centre, Jalan Yaacob Latif, Bandar Tun Razak, 56000

Cheras, Kuala Lumpur, Malaysia.

Background and aims: Precise and early prediction of acid-base disturbances in critically ill patients are crucial for timely management. This study aimed to compare bedside corrected anion gap (cAG) and standard base excess (sBE) for detection of unmeasured anions (UA) with the gold standard of corrected base excess (CBE) approach. The association between $\mathrm{CAG}$ and $\mathrm{sBE}$ in hyperlactataemia and increased mortality among critically ill patients were determined.

Materials and methods: This retrospective observational study involved 229 patients admitted beyond 24 hours to Intensive Care Unit (ICU), Universiti Kebangsaan Malaysia Medical Centre (UKMMC) between September and December 2016. The demographical and biochemical data were retrieved from the Medical Records Department, UKMMC.

Results: Findings were analysed for its sensitivity (Sn), specificity (Sp), positive and negative predictive value (PPV, NPV) and positive and negative likelihood ratio (positive LR, negative LR) as predictors of UA. The cAG had an Sp, PPV, NPV, positive and negative LR of $96.4 \%, 83.3 \%, 98.8 \%, 22.5$ and 15.3 respectively. The sBE had lower predictive values (Sp: 81.5\%, PPV: 49.2\%, NPV: 98.6\%, positive LR: 5.1 and negative LR: 13.1). Both had similar $\mathrm{Sn}$ at $93.8 \%$. All the predictors of UA were predisposed to hyperlactataemia (cAG: OR 31.83, 95\% Cl 12.03-84.20, $p<0.001$; sBE: OR 15.39, 95\% Cl 5.87-40.37, $p<0.001$; cBE: OR 51.11, 95\% Cl 17.92$145.75, p<0.001$ ) and increased ICU mortality (cAG: OR 11.75, 95\% Cl 5.21-26.47, $p<0.001$; sBE: OR 15.20, 95\% Cl 6.18-34.42, $p<0.001$; cBE: OR 23.53, 95\% Cl 9.27$59.73, p<0.001)$, respectively.

Conclusion: The cAG is a better bedside tool for predicting UA compared to sBE. All $c A G, s B E$ and $c B E$ in the presence of high levels of UA are predisposed to hyperlactataemia and increased ICU mortality.

Keywords: Unmeasured Anions, Hyperlactataemia, Intensive Care Unit, Acid Base Imbalance. 


\title{
Clinical Year Student's Perception and Evaluation on Pharmacology Teaching
}

\author{
MOHAMAD SHARIF MA ${ }^{1}$, NORAIN MM'1 ${ }^{1}$ MUHAMMAD ADAM \\ AC $^{1}$, HAZLINDA $M^{1}$, DARISHINI ${ }^{1}$, NORAZLINA $M^{1}$, SITI \\ MARIAM B ${ }^{2}$
}

\begin{abstract}
'Department of Pharmacology, ${ }^{2}$ Department of Medical Education, Faculty of Medicine, Universiti Kebangsaan Malaysia Medical Centre, Jalan Yaacob Latif, Bandar Tun Razak, 56000 Cheras, Kuala Lumpur, Malaysia.
\end{abstract}

Background and aims: The aim for obtaining students' perception was meant for the review of teaching methodologies. Pharmacology teaching during pre-clinical is important for students to make rational choices in choosing suitable treatment for patients in the future. The present study aimed to determine the effectiveness of current method of Pharmacology teaching and obtain suggestion for improvement, which is essential for curriculum improvement.

Materials and methods: An online questionnaire on perception in pharmacology teaching methodology, was distributed to a total of 547 students, which consisted of $4^{\text {th }}$ and $5^{\text {th }}$ year medical students in Universiti Kebangsaan Malaysia Medical Centre. The questionnaire included five parts: demographics, attitude and perception about Pharmacology, the ideal teaching learning method for learning Pharmacology, Pharmacology topics, which are useful for future clinical practice, and lastly Pharmacology topic, which was most interesting.

Results: The respond rate was $45 \%$. The majority of the participants were female $(68 \%), 5^{\text {th }}$ year $(54.7 \%)$, Malay $(72.5 \%)$, and originated as Universiti Kebangsaan Malaysia students $(57.5 \%)$. Most students agreed that interactive learning was more helpful than didactic lectures $(88.0 \%)$. The percentage of students that find pharmacology lectures in pre-clinical helpful for clinical years is $70.8 \%$. A percentage of $45.6 \%$ of students agreed that Pharmacology teaching in pre-clinical was adequate for clinical practice. The association between demographic variables (gender, race, year of study and medical family background) was $p>0.05$.

Conclusion: Current syllabus is effective for clinical practice. The most preferred teaching method was Problem Based Learning (PBL). Students perceived that the Pharmacology teaching in pre-clinical is adequate for clinical year practice. There was no significant association between demographic data and student's interest in Pharmacology.

Keyword: Pharmacology, Medical Student, Teaching, Methodology, Feedback 


\title{
The Effect of Virgin Coconut Oil on Fibroblasts and Collagen Fibres in Diabetic Wound Healing
}

\author{
SOON KUEN W, THANUSHA R, NOR SYAQIRA AB, WAN \\ NAZMI AI, ERIN ELLIEY FB, ABD RAHIMAN MA, SOLIMAN AM, \\ NORZANA AG, DAS S, TEOH SL
}

Department of Anatomy, Faculty of Medicine, Universiti Kebangsaan Malaysia Medical Centre, Jalan Yaacob Latif, Bandar Tun Razak, 56000 Cheras, Kuala Lumpur, Malaysia.

Background and aims: Delayed wound healing is one of the major complications of diabetes mellitus where it often leads to amputation. Virgin coconut oil (VCO) is natural oil widely used to treat wounds and burns traditionally. It possesses potent antioxidant and antibacterial activities. The aim of this study was to determine the effect of VCO on fibroblast and collagen fibres deposition in diabetic wound healing.

Materials and methods: Full thickness cutaneous wound tissues were collected from non-treated, VCO-treated, and silver sulfadiazine cream (SS)-treated diabetic rats. The tissues were then subjected to Verhoeff van Gieson staining and immunohistology of fibroblast; myofibroblast and collagen type 1 fibre.

Results: Histological analysis showed increased collagen deposition with intact epidermis in the VCO treated group compared to decreased collagen deposition with damaged epidermis in both non-treated and SS-treated groups. Similarly, more fibroblasts were observed in the VCO treated group compared to the non-treated and SS-treated groups.

Conclusion: In summary, VCO significantly promoted wound-healing process in diabetic rats via promoting re-epithelialization, and increasing collagen fibres deposition and wound contraction. The results suggested that VCO could be used to treat diabetic wounds.

Keywords: Immunohistochemistry, Diabetes Mellitus, Cutaneous, Regeneration 


\title{
The Prevalence and Associated Factors of Premature Ejaculation and Erectile Dysfunction among Patients on Antidepressants in a Malaysian Teaching Hospital
}

\author{
IUN YI L프, MOHAMMAD IZZAT NK'1, JAMUNA V', NUR \\ DIYANAH T ${ }^{1}$, NUR DIANA AF ${ }^{1}$, HATTA $S^{1}$, SHALISAH $\mathrm{S}^{1}$, JIANN \\ LIN L1,2
}

\begin{abstract}
${ }^{1}$ Department of Psychiatry, Faculty of Medicine, Universiti Kebangsaan Malaysia Medical Centre, Jalan Yaacob Latif, Bandar Tun Razak, 56000 Cheras, Kuala Lumpur, Malaysia.

${ }^{2}$ Faculty of Medicine and Sciences, Universiti Malaysia Sabah.
\end{abstract}

Background and aims: Sexual problems are common among patients who are on antidepressants treatment. The objective of this study was to determine the prevalence of premature ejaculation (PE) and erectile dysfunction (ED), and their potential risk factors that may impair their sexual function in a teaching hospital (TH).

Materials and Methods: A cross-sectional study using simple random sampling was conducted among adult male patients who were on antidepressant treatment in the TH psychiatric outpatient clinic. Respondents' socio-demographic data were obtained. Participants were interviewed using a structured self-report questionnaire with 15-item International Index of Erectile Function (IIEF-15) where the scores lesser than 25 were indicative for having an ED. A validated Malay Premature Ejaculation Diagnostic Tool (MAPET) was used to assess PE and those with a score $\geq 23$ were considered to have PE.

Results: Hundred respondents participated, and the prevalence of PE and ED was $66 \%$ and $85 \%$, respectively. Using multivariate binary logistic regression, the potential risk factors of PE were race, i.e. being non-Malay $(p=0.044)$, lesser in the frequency of sexual activity $(p=0.03)$ and also an $E D(p=0.03)$, respectively. The only risk factor for ED was PE $(p=0.026)$. No significant association was noted for the other factors, including type of the antidepressant, dose and duration of antidepressant used ( $p>0.05)$. There was a strong correlation of MAPET and IIEF-15 $(r=-0.345, p<0.01)$ signifying patient with more severe PE had more severe ED.

Conclusions: Due to very high rate of ED and PE in this group of respondents, it is pivotal to screen for sexual problem among patients who are taking an antidepressant in a psychiatric set-up.

Keywords: Premature Ejaculation, Erectile Dysfunction, Risk Factors, Psychopharmacology 


\title{
Molecular Detection of Infective Pathogens in Patients with Inflammatory Bowel Disease of Different Disease Status
}

\author{
SYAFIQA AL-AZUA A ${ }^{1}$, SARAH HANIS CMA ${ }^{1}$, VIGNESWARI AK', \\ AUGUSTIN MSK' ${ }^{1}$, MUHAMMAD AZAM S ${ }^{1}$, MUTTAQILLAH \\ NAJIHAN AS ${ }^{1}$, HAMIDAH ${ }^{1}{ }^{1}$, ZETTI ZR ${ }^{1}$ RAJA AFFENDI RA ${ }^{2}$
}

\begin{abstract}
${ }^{1}$ Department of Medical Microbiology \& Immunology, ${ }^{2}$ Gastroenterology Unit, Department of Medicine, Faculty of Medicine, Universiti Kebangsaan Malaysia Medical Centre, Jalan Yaacob Latif, Bandar Tun Razak, 56000 Cheras, Kuala Lumpur, Malaysia.
\end{abstract}

Background and aims: Patients with inflammatory bowel disease (IBD) either Crohn's disease (CD) or ulcerative colitis (UC) commonly predispose to many microbial infections regardless of their disease status. Microbial infection can mimic flares of IBD and this can lead to delaying the active management of IBD cases. However, screening for microbial infections among IBD patients is not widely practiced. This study aimed to detect the presence of pathogens in both active and inactive IBD patients.

Materials and methods: A cross-sectional study was performed from January to December 2017 at the Universiti Kebangsaan Malaysia Medical Centre. Stool samples were collected from both active and inactive IBD patients. Patients who were on antibiotics or corticosteroid therapy and paediatric population were excluded. The samples were analyzed for 26 pathogens using multiplex real-time polymerase chain reaction (PCR) by Seegene Allplex ${ }^{\mathrm{TM}}$ gastro-intestinal panels.

Results: A total of 24 IBD patients were recruited (9 CD, 15 UC; 14 active and 10 inactive). Nine patients (37.5\%) had one pathogen detected, and ten patients $(41.7 \%)$ had two to three pathogens. The most common infective pathogens detected for active and inactive IBD patients were Enteropathogenic Escherichia coli (45.8\%), Enteroaggregative Escherichia coli (25.0\%) and Aeromonas spp. (16.7\%). Other pathogens detected were Escherichia coli O157 (12.5\%), Salmonella spp. (8.3\%), Clostridium difficile toxin B (8.3\%), Enterotoxigenic Escherichia coli (8.3\%), Enterohemorrhagic Escherichia coli (4.2\%) and Blastocystis hominis (4.2\%). All active IBD cases were treated as flares of disease and none were treated for microbial infections.

Conclusion: Multiple infective pathogens particularly Escherichia coli were predominantly detected in IBD patients regardless of their disease status. Early detection of this infective pathogen is vital as therapy for the flares of IBD cases and infections can be managed simultaneously.

Keywords: Ulcerative Colitis, Crohn Disease, Multiplex Polymerase Chain Reaction, Gastrointestinal Tract, Infection 


\title{
Effect of Gynura procumbens Standardised Extract on Oxidative Status of Atherosclerotic Rat Model
}

\author{
MOHAMED SHAJAARUDDIN I, KUI ZHENG B, WAN NOOR \\ AWO, ZAKIAH J
}

Department of Biochemistry, Faculty of Medicine, Universiti Kebangsaan Malaysia

Medical Centre, Jalan Yaacob Latif, Bandar Tun Razak, 56000 Cheras, Kuala Lumpur,

Malaysia.

Background and aims: Atherosclerosis is caused by oxidative stress that results in cellular oxidative damage. Gynura procumbens contains antioxidant properties that might overcome the oxidative damage. This study aimed to determine the effect of Gynura procumbens standardised extract on oxidative status of the atherosclerotic rat model.

Materials and methods: Forty-eight of Sprague-Dawley(SD) rats were divided into control, Gynura procumbens (GP) with $250 \mathrm{mg} / \mathrm{kg}$, GP with $500 \mathrm{mg} / \mathrm{kg}$, atorvastatin, atherosclerotic model, atherosclerotic with $250 \mathrm{mg} / \mathrm{kg}$, atherosclerotic with 250 $\mathrm{mg} / \mathrm{kg}$ and atherosclerotic with atorvastatin. Treatment was given for 24 weeks. The plasma malondialdehyde (MDA) level was measured using High-performance liquid chromatography (HPLC). Antioxidant enzyme activity; superoxide dismutase (SOD), catalase (CAT) and glutathione peroxidase (GPx) in red blood cells were determined by spectrophotometer.

Results: Malondialdehyde (MDA) level was increased at 3 and 6-month duration in the atherosclerotic rat model compared to control and was reduced with GP extract supplementation. CAT and GPx activity were reduced in atherosclerotic group, but no changes with SOD activity. GP extract at $250 \mathrm{mg} / \mathrm{kg}$ and $500 \mathrm{mg} / \mathrm{kg}$ increased $(p<0.05)$ CAT and GPx activity compared to atherosclerotic group.

Conclusion: Gynura procumbens has the ability to reduce membrane lipid peroxidation in atherosclerosis and most probably, it is through the modulation of antioxidant enzyme activity.

Keywords: Antioxidants, Atherosclerosis, Malondialdehyde, HPLC 


\title{
Effects of Kelulut Honey on Viability and Oxidative Stress Level of Autism Lymphoblastoid Cell Line (ALCL)
}

\author{
NAZATUL SN, MUHAMMAD AIMAN MY, KAMACHISREE \\ N, AMIRUL ASYIQ A, NUR SYUHAIDAH Z, HAZIRAH H, \\ NORWAHIDAH AK
}

Department of Biochemistry, Faculty of Medicine, Universiti Kebangsaan Malaysia Medical Centre, Jalan Yaacob Latif, Bandar Tun Razak, 56000 Cheras, Kuala Lumpur, Malaysia.

Background and aims: Kelulut honey is known for its high antioxidant properties. High level of oxidative damage was found in autism. This study aimed to determine the effects of Kelulut honey on the viability and oxidative stress level in ALCL.

Materials and methods: Cells [Non-ALCL $(\mathrm{NALCL})$ and $\mathrm{ALCL}$ ] were cultured in Roswell Park Memorial Institute (RPMI) media (5\% of Carbon dioxide at $37^{\circ} \mathrm{C}$ ). The cells were divided into 3 groups: untreated NALCL, honey-treated $A L C L$ and untreated ALCL. The optimum dose of honey was obtained from MTS assay and was used for subsequent analysis. Oxidative stress marker i.e. malondialdehyde (MDA) and antioxidant enzymes activity i.e. catalase (CAT), glutathione peroxidase (GPx) and superoxide dismutase (SOD) were measured by enzyme-linked immunoassay kit while DNA damage was measured using comet assay.

Results: Optimum dose of Kelulut honey for cell viability indicated by MTS assay was $400 \mu \mathrm{g} / \mathrm{l}$. ALCL treated with Kelulut honey exhibited a significant increase in SOD level compared to untreated ALCL $(p<0.05)$. CAT and GPx did not show any significant changes between treated ALCL and untreated ALCL ( $p>0.05)$. MDA level in treated $A L C L$ did not show any significant changes with untreated $A L C L(p>0.05)$. Comet assay showed that the treatment reduced the grade 2 DNA damage in treated ALCL significantly compared to untreated ALCL $(p<0.05)$. Meanwhile, MDA level in NALCL was significantly lower compared to untreated ALCL $(p<0.05)$. Comet assay showed there was significantly higher grade $3 \mathrm{DNA}$ damage in untreated $\mathrm{ALCL}$ than NALCL $(p<0.05)$ while a significant higher grade 0 and 1 DNA damage was found in NALCL than untreated ALCL $(p<0.05)$.

Conclusion: ALCL showed lower antioxidant enzyme activities and higher MDA level compared to NALCL. However, treatment with Kelulut honey in ALCL successfully reduced the oxidative stress (reduced MDA level) by increasing the antioxidant enzymes activity.

Keywords: Antioxidant, Enzymes, Autism, Malondialdehyde, Comet Assay, Catalase 


\title{
Burden and Negative Emotional State among Caregivers of Patients with Different Advanced Diseases
}

\author{
NUR FAZLIN ${ }^{1}{ }^{1}$, HANIF $\mathrm{A}^{1}$, SELVAVINAYAGAN PS ${ }^{1}$, NORLINA K', \\ REENA RISHINEE JS', HAYATI Y' ${ }^{1}$, SHAMSUL AS ${ }^{2}$ \\ ${ }^{1}$ Department of Medicine, ${ }^{2}$ Department of Community Health, Faculty of Medicine, \\ Universiti Kebangsaan Malaysia Medical Centre, Jalan Yaacob Latif, Bandar Tun Razak, \\ 56000 Cheras, Kuala Lumpur, Malaysia.
}

Background and aims: Caregivers play crucial role in the care of patients with advanced diseases and this may affect their quality of life. Each different illness may have different needs of care either physical or psychological aspects. This study aimed to determine the prevalence of care burden and negative emotional state of the carers in five types of advanced diseases and their correlation.

Materials and methods: This was a cross-sectional prospective study of carers in a tertiary health institution. Respondents were asked to complete the Zarit Burden scale (Zarit 22) and the Depression, Anxiety and Stress Scale 21 (DASS21) questionnaires based on their experiences.

Results: The response rate was $80 \%(n=200)$. Majority of respondents were females with a mean age of $45.61 \pm 14.78$ years. The mean age of patients was $65.41 \pm 14.78$ years. The mean total Zarit score of carers was $22.73 \pm 12.97$, indicating a mild to moderate level of burden $(p<0.001)$. Carers' burden was the highest among chronic obstructive pulmonary disease (COPD) patients, with a mean total Zarit score of $25.64 \pm 12.80$, followed by stroke $24.65 \pm 12.23$, cancer $24.16 \pm 14.35$, heart failure $20.13 \pm 13.97$ and end-stage renal failure (ESRF) $17.47 \pm 8.37$. The difference in Zarit score among the groups was statistically significant $(p<0.001)$. It was observed that $43 \%$ of the caregivers were depressed, $58.0 \%$ were anxious and $30 \%$ were stress. Caregivers for COPD patients were highly depressed $(72.7 \%)$ and anxious $(78.8 \%)$ compared to other illnesses $(p<0.001)$. There was a strong association $(p<0.001)$ between negative emotional states of the carers and care burden. No statistically association between risk factors and negative emotional states was identified except for race $(p<0.001)$.

Conclusion: Better understanding of pattern and need of patients with advanced illnesses may reduce care burden and negative emotional state among caregivers.

Keywords: Caregiver, Burden, Negative Emotion, Functional Status, COPD 


\title{
Satisfaction Study of Smartphone Related Communication Application Services for Patient Related Care Among Doctors at a Tertiary Referral Centre in Malaysia
}

\author{
LOSHUA DASS D' 1 , MUHAMMAD IMRAN QAZ ${ }^{1}$, MURNI ATIKAH \\ N', ARIKA KA ${ }^{1}$, SHALINI V'1, MLC BASTION'1, SHAMSUL AZHAR S² \\ ${ }^{1}$ Department of Ophthalmology, ${ }^{2}$ Department of Public Health, Faculty of Medicine, \\ Universiti Kebangsaan Malaysia Medical Centre, Jalan Yaacob Latif, Bandar Tun Razak, \\ 56000 Cheras, Kuala Lumpur, Malaysia.
}

Background and aims: The use of smartphone applications as a tool of communication in healthcare setting are increasing. Doctors use these applications to deliver patients' related clinical information to their colleagues, superiors or subordinates. This study was conducted to measure the level of satisfaction among doctors in using the mobile communication applications (MCA) to discuss workrelated issues.

Materials and methods: This was a cross-sectional study involving 252 doctors that were selected using stratified random sampling from 13 clinical departments of a tertiary referral hospital in Cheras, Malaysia. A standardised self-administered questionnaire (SAQ) (validated with a Cronbach's Alpha value of 0.909) was used in this study. Five-point Likert scale questions with total score of 70 were used to study the level of satisfaction among participants. The cut-off point for satisfaction was set at $80 \%$.

Results: A total of 252 doctors participated in this study, in which $40(15.9 \%)$ were consultants, 26 (10.3\%) were specialist and 186 (73.8\%) were medical officers. Their mean age was 34.41 years. The respondents consisted of $152(60.3 \%)$ women and $100(39.7 \%)$ men. Among the respondents, 163 (64.7\%) were Malays, 57 (22.6\%) Chinese, $24(9.5 \%)$ Indians and 8 (3.2\%) belonged to other ethnicities. The main objectives of using MCA were work (119 or $47.2 \%$ ) and social communication (118 or $46.8 \%)$. The satisfaction level of using MCA among consultants, specialists and medical officers were $15 \%, 50 \%$ and $36 \%$, respectively. There was a significant difference in the satisfaction level between doctors with different positions $(p=0.008)$. Based on the information received via MCA, 58.3\% doctors were unable to make a proper diagnosis and $51.2 \%$ were unable to plan the proper management. This observation was not significantly different between doctors with different positions ( $p>0.05)$. 
Conclusion: Majority of doctors were not satisfied in using MCA in patient related care.

Keywords: Satisfaction, Smartphone, Patient, Clinical 


\title{
The Predictive Role of Hand and Foot Dimensions in the Estimation of Stature among Malaysian Population
}

\author{
DAANIYAL REESHA R, AISHAH M, KOTHAI M, LAKHNESWARAN \\ K, SONIA J, FARIDAH MN
}

Forensic Unit, Department of Pathology, Faculty of Medicine, Universiti Kebangsaan

Malaysia Medical Centre, Jalan Yaacob Latif, Bandar Tun Razak, 56000 Cheras, Kuala

Lumpur, Malaysia.

Background and aims: Stature is one of the useful anthropometric parameters of an individual. Estimation of stature plays a significant role in establishing personal identity, particularly in dismembered remains during mass disaster, murder and accident. This study aimed to derive Malaysian population-specific regression to estimate stature from hand and foot dimensions.

Materials and methods: A prospective and cross-sectional study was done in 400 staffs and students, who were randomly chosen from Universiti Kebangsaan Malaysia Medical Centre ranging from 19 to 60 years old. The subjects comprised 200 male and 200 female from three major races (Malay, Chinese, Indian) in Malaysia. There were 11 parameters measured including hand length 1, hand length 2, hand length 3, hand length 4, hand length 5, hand length, palm length, hand breadth, maximum hand breadth, foot breadth and foot length, which were measured by a measuring tape and Vernier callipers. The measurements were taken twice and averaged.

Results: Results showed that all parameters exhibited significant differences between sexes and between right and left sides $(p<0.05)$. Of the parameters, hand breadth, maximum hand breadth and foot breadth showed significant differences among ancestry $(p<0.05)$. Additionally, foot length $(r=0.83 ; p<0.05)$, hand length $3(r=0.80 ; p<0.05)$ and hand length $4(r=0.78 ; p<0.05)$ showed good correlations with stature in that sequence. The estimated stature and true stature demonstrated good approximation of values. Hence, the regressions constructed have provided the best approximation of stature in this research project.

Conclusion: In brief, this study provided regressions for stature estimation from hand and foot dimensions. It is hoped that these equations can be used for stature estimation in the Malaysian population. Further study is needed to evaluate the results in this research project.

Keywords: Forensic, Anthropology, Stature, Malaysian, Identification 


\title{
A Survey of Knowledge in Antibiotic Resistance, Perscription and Usage among Medical Students
}

\author{
THIBAN PILLAI PP, MUHAMAD SYAHMI A, DIVEYASHENI D, \\ NUR HAFIZAH AR, NAJIHAH FARHANA H, FAHRIN ZARA MN
}

Department of Otorhinolaryngology and Head and Neck Surgery, Faculty of Medicine, Universiti Kebangsaan Malaysia Medical Centre, Jalan Yaacob Latif, Bandar Tun Razak, 56000 Cheras, Kuala Lumpur, Malaysia.

Background and aims: The emergence of antibiotic resistance poses a significant threat to modern medicine. The study aimed to determine the knowledge, attitude, practice (KAP) and perception of medical students towards antibiotic prescription and resistance.

Materials and methods: A cross-sectional study was conducted in a tertiary referral hospital in Cheras, Malaysia. A total of 238 year 5 medical students were recruited as the respondents in this study. The questionnaires were distributed to the respondents and they were required to answer the questions independently. Data collection was carried out for 3 months.

Results: Total sample amounted to 254 fifth year medical students, with more participation from female students $(71.3 \%)$ compared to male students $(28.7 \%)$. This study found that female medical students had statistically significant higher marks in confidence in prescribing $(27.65 \pm 5.68)$ compared to male students $(26.03 \pm 5.29)$ $(p=0.037)$. There was also a statistically significant association $\left(\chi^{2}=3.996, p=0.046\right)$ between level of confidence in prescribing and level of attitude towards antibiotics use. Poor level of knowledge on antibiotics use was found in $68 \%$ of respondents. Of note, $4 \%$ of the students incorrectly thought that antibiotics could be used to treat bacterial infection. About $95 \%$ of the respondents had good positive attitude towards antibiotics use.

Conclusion: This study showed that there are gaps in terms of knowledge, attitude and confidence level in the use and prescription of antibiotics among medical students. Misconception on antibiotics is prevalent among final year medical students. These findings would be useful in improving the medical curriculum in Malaysia.

Keywords: Antibiotic resistance, Medical Students, Upper Respiratory Tract Infection 


\title{
A Retrospective Study of Factors Contributing to Maturation Rate of Brachio-Cephalic Fistula in Universiti Kebangsaan Malaysia Medical Centre
}

\author{
NORATUL ATIKAH S, HEKNESVARAAN B, MUHAMMAD \\ ZUHAILY I, KOTHAINACHI PR, MURNI H, LENNY SURYANI S, \\ MOHD AMIRRULLAH SZ, MOHAMAD AZIM MI, HANAFIAH H
}

Department of Surgery, Faculty of Medicine, Universiti Kebangsaan Malaysia Medical Centre, Jalan Yaacob Latif, Bandar Tun Razak, 56000 Cheras, Kuala Lumpur, Malaysia.

Background and aims: Brachio-cephalic fistula (BCF) is a popular arteriovenous fistula. This study aimed to identify the prevalence of BCF maturation and to determine predictors that affect the BCF maturation rate.

Materials and methods: A retrospective study of database review was conducted to identify all BCF creation performed in Universiti Kebangsaan Malaysia Medical Centre from 2014 to 2016. Defaulted patients were excluded. Patients who underwent vein scan and met all the standard criteria for BCF creation, arterial size minimum $2.5 \mathrm{~mm}$, good blood flow and good vein which was fully compressed and no thrombus, were included in this research. The comorbid factor and the correlation with the maturation of BCF were identified.

Results: A total of 215 patients, age ranging from 30-80 years, were included in this study. Majority of them had underlying comorbidities such as diabetes mellitus (DM), hypertension (HTN) and ischaemic heart disease (IHD). From all 215 BCFs included in the study, 94 were women and 121 were men. The overall BCF maturation rate in the study was $91.2 \%(196 / 215)$. Age, gender and race did not influence the maturation rate $(p<0.05)$. The maturation rate for patients with the vein diameter of less than $2.5 \mathrm{~mm}(85.3 \%)$ was lower compared to those with vein diameter of more than $2.5 \mathrm{~mm}(94.3 \%)(p=0.028)$. The maturation rate in patient with IHD was lower $(79.3 \%)$ compared to those without IHD $(93 \%)(p=0.016)$. Other predictors like DM $(p=0.417)$ and HTN $(p=0.535)$ did not influence the maturation.

Conclusion: In conclusion, vein diameter of less than $2.5 \mathrm{~mm}$ and ischaemic heart disease are negative predictors of the BCF maturation.

Keywords: Chronic Kidney Disease, Diabetes Mellitus, Dialysis 


\title{
Decellularization and Genipin Crosslinking of Amniotic Membrane Suitable for in Vitro Airway Epithelium Construction
}

\author{
SARUMATHI G ${ }^{1}$, SITI SOLEHAH Z1', SITI FATMAH A', MOHAMAD \\ NABIL IA ${ }^{1}$, RAJASEGARAN ${ }^{1}{ }^{1}$, SALINA H${ }^{2}$, NOR HASLINDA AA ${ }^{3}$, \\ YOGESWARAN L ${ }^{1}$
}

\begin{abstract}
${ }^{1}$ Tissue Engineering Centre, ${ }^{2}$ Department of Otorhinolaryngology - Head and Neck Surgery, ${ }^{3}$ Department of Obstetrics and Gynaecology, Faculty of Medicine, Universiti Kebangsaan Malaysia Medical Centre, Jalan Yaacob Latif, Bandar Tun Razak, 56000

Cheras, Kuala Lumpur, Malaysia.
\end{abstract}

Background and aims: Airway epithelium can be affected by various threats, which can progress into respiratory diseases. Amniotic membrane has potential as biological scaffold for in vitro and in vivo tissue regeneration in research and clinical use. This study investigated the characteristic of native, decellularized and Genipin cross-linked amniotic membrane as a suitable scaffold for in vitro airway epithelium construction.

Materials and methods: Redundant human amniotic membranes (HAM) were collected from consented patients who underwent lower segment caesarean sections (LSCS) in Universiti Kebangsaan Malaysia Medical Centre. The HAM were then processed and categorized into native (nAM), decellularized (dAM) and genipin cross-linked (cIAM) in $3 \times 3 \mathrm{~cm}$ size. The decellularizations of HAMs were conducted using thermolysin (TL) and sodium hydroxide $(\mathrm{NaOH})$. Next, HAMs in clAM group were cross-linked with $0.5 \%$ and $1.0 \%$ Genipin. The HAMs were tested for optical clarity, in vitro degradation and percentage of swelling ratio. Meanwhile, redundant nasal turbinate was collected from consented patients who underwent turbinectomy and fibroblasts were isolated. Fibroblasts at passage 3 were then seeded onto the HAMs for biocompatibility studies. Scanning electron microscopy and mechanical stress measurement are ongoing.

Results: In vitro degradation test showed cIAM had the slowest degradation rate, which was morphologically intact after 24 hours incubation, whereas nAM and dAM had completely degraded after 4 and 11 hours, respectively. The dAM had the greatest transparency compared to others. The $0.5 \%$ clAM had a greater clarity than $1.0 \% \mathrm{clAM}$. The dAM had a significantly highest percentage of swelling ratio than other groups $(\mathrm{p}<0.05)$. However, there were no significant differences between $0.5 \%$ and $1.0 \%$ clAM. The immunocytochemistry analysis showed clAM had lesser protein retention compared to both nAM and dAM. 
Conclusion: The cIAM is mechanically stronger and suitable for in vitro airway epithelium construction compared to other groups.

Keywords: Respiratory Epithelium, Fibroblast, Scaffold, Tissue Regeneration 


\title{
Comparative Exposure of Xylene and Wintergreen Oil in Maggot Slide Preparation in Forensic Entomology Analysis
}

\author{
MUHAMMAD FARID MT, NURUL AQILAH K, PRAVEENDURAI \\ K, SHALINI J, AMEERAH M, AISHAH HANI A, AHMAD FIRDAUS \\ MS, SYAMSA RIZAL A
}

Department of Parasitology \& Medical Entomology, Faculty of Medicine, Universiti Kebangsaan Malaysia Medical Centre, Jalan Yaacob Latif, Bandar Tun Razak, 56000

Cheras, Kuala Lumpur, Malaysia.

Background and aims: Forensic entomology is a study of insects that form part of the evidence in legal cases, which is mainly associated with death enquiries. Correct identification of maggot species may assist investigations by providing information on time, place or manner of a crime committed. A single maggot slide preparation requires 190 minutes and long exposure to xylene throughout the mounting process. However, xylene is proven to be hazardous to human health and also the environment. Therefore, this study was aimed to determine the capability of wintergreen oil to substitute xylene as clearing agent in third instar larvae maggot slide preparation, as well as to suggest a modified method to reduce the time of maggot slide preparation.

Materials and methods: A total of 240 third instar larvae of Hemipyrellia ligurriens (Wiedemann) (Diptera: Calliphoridae) were collected from rat carcasses that were left at an open field. These maggots were then preserved in $70 \%$ alcohol. In the laboratory, the larvae samples were divided into four groups, namely A (xylenestandard time), B (wintergreen-standard time), C (xylene-modified time), and D (wintergreen-modified time) and processed accordingly. The morphological features of each specimen (cephalopharyngeal skeleton, spine and posterior spiracle) were compared under the microscope. The parameter used for the scoring of slides was clarity of morphological features.

Results: There was no significant difference of morphological features between the standard and modified procedure using xylene $(p=0.309)$ and wintergreen oil $(p=0.315)$ in terms of immersion time. Meanwhile, in term of clearing agent, the morphological features also show no significant difference between xylene and wintergreen in standard procedure $(p=0.309)$ and modified procedure $(p=0.315)$.

Conclusion: Therefore, wintergreen can be used as a substitute for xylene for safety purposes and the modified method can be used to reduce time and health hazard.

Keywords: Calliphoridae, Methyl Salicylate, Clearing Agent 


\title{
Protective Effect of Chlorella vulgaris on Deoxyribonucleic Acid Damage, Oxidative Stress and Lung Morphological Changes in Cigarette Smoke- Exposed Rats
}

\author{
KAMARUL SYARIZA Z' ${ }^{1}$, MUHAMAD KHAIRUL NN', FARAH \\ IZZATI D' ${ }^{1}$, DIANA GEORGE E' ${ }^{1}$ NOOR DEANNA AR ${ }^{1}$, NUR \\ HAZIRAH $R^{1}$, FAIRUS $A^{2}$, FAZARINA $M^{3}$, YASMIN ANUM MY ${ }^{1}$ \\ ${ }^{1}$ Department of Biochemistry, ${ }^{2}$ Department of Anatomy, ${ }^{3}$ Department of Pathology, \\ Faculty of Medicine, Universiti Kebangsaan Malaysia Medical Centre, Jalan Yaacob Latif, \\ Bandar Tun Razak, 56000 Cheras, Kuala Lumpur, Malaysia.
}

Background and aims: Chlorella vulgaris (ChV) is a unicellular fresh water alga with antioxidant and anti-inflammatory effects. The aim of this study was to determine the protective role of ChV on deoxyribonucleic acid (DNA) damage, oxidative stress and lung morphological changes in cigarette smoke-exposed rats.

Materials and methods: Twenty-four male Sprague Dawley rats (200-250g), aged between 7-9 weeks were divided into 4 groups of 6 rats in each group: Control, $\mathrm{ChV}(300 \mathrm{mg} / \mathrm{kg}$ body weight), cigarette smoke-exposed rats, and cigarette smokeexposed rats treated with ChV. Blood samples were drawn from the orbital sinus at days 0,15 and 30 for the determination of DNA damage by Comet assay and plasma malondialdehyde (MDA) using High Performance Liquid Chromatography (HPLC). Rats were killed at day 30 and lung tissue samples were taken for the evaluation of airspace enlargement, inflammation, and goblet cell hyperplasia.

Results: Increased DNA damage and MDA levels in cigarette smoke-exposed rats were reduced significantly $(p<0.05)$ when treated with $\mathrm{ChV}$. Hematoxylin and Eosin (H\&E) staining showed that all cigarette smoke-exposed rats had high frequency of airspace enlargement, and increase in inflammatory and goblet cells. Reduced frequency of airspace enlargement and number of inflammatory cells were observed in cigarette smoke-exposed rats treated with ChV, but no changes in number of goblet cells was found.

Conclusion: ChV has a protective role in cigarette smoke-exposed rats by reducing oxidative DNA damage, MDA levels, lung cells inflammation and airspace enlargement.

Keywords: Malondialdehyde, Goblet Cells, Antioxidant, Emphysema, Histology 


\title{
A Study of Overnight Transfusion Practice in Universiti Kebangsaan Malaysia Medical Centre
}

\author{
IEMA LINA R, WAN MUHAMMAD WN, JULAINA ZA, VICTORIA \\ ROS RN, RABEYA Y, CHOOI FUN L, YEE LOONG T
}

\begin{abstract}
Department of Pathology, Faculty of Medicine, Universiti Kebangsaan Malaysia Medical Centre, Jalan Yaacob Latif, Bandar Tun Razak, 56000 Cheras, Kuala Lumpur, Malaysia.
\end{abstract}

Background and aims: Overnight transfusion (OT) is blood transfusion that occurs from $9 \mathrm{pm}$ to $8 \mathrm{am}$. However, during this period, there are less number of staff to monitor patients closely during transfusion and this may lead to higher risk of errors. Hence, a cross-sectional study was done to determine the incidence and practice of OT in Universiti Kebangsaan Malaysia Medical Centre.

Materials and methods: All OTs in June and July 2017 were identified. The relevant data on three phases of OT namely pre-transfusion, during transfusion and post-transfusion were collected from transfusion recipients' cards, group and cross match (GXM) forms and patients' case notes and analysed.

Results: A total of 340 cases of OTs (16.8\%) were identified out of 2021 total transfusions in two months. Around $17.1 \%$ cases were considered as unnecessary transfusion in which the clinical indications were divided into less acute clinical need $(12.5 \%)$ and no clinical need (4.6\%). The major reason that led to OTs was a huge delay (mean of 8 hours) in starting transfusion after GXM completed with $32.9 \%$ cases recorded a delay of $>12$ hours. Besides, $27.6 \%$ cases took $>4$ hours to complete OT; $83.6 \%$ cases did not have proper transfusion monitoring as recommended, and three transfusion reactions reported.

Conclusion: In conclusion, the practice of OT should be discouraged wherever possible for patient safety except for clinically indicated cases because most of overnight transfusion have posted risks and may endanger patients' life if an adverse transfusion reaction happened. Hence, clinical staff should begin transfusion early once GXM completed to avoid OT as well as the contravention of 4-hour infusion rule, indirectly expose the patients to the risk of bacterial sepsis and spontaneous haemolysis.

Keywords: Blood Safety, Transfusion Reactions, Blood Cross Matching, Packed Cell 


\title{
Depression, Anxiety and Quality of Life in Adolescent Idiopathic Scoliosis
}

\author{
MOHD AMIR ACMD ${ }^{1}$, NOR AISHAH A ${ }^{1}$, AQILA R ${ }^{1}$, SHOBANA \\ DEVI K', MUHAMMAD AIZZUL AI ${ }^{1}$, JIANN LIN L ${ }^{1,3}$, AZMI B ${ }^{2}$, \\ KAMALNIZAT I², MOHD HISAM MA², AZLIN B ${ }^{1}$
}

${ }^{1}$ Department of Psychiatry, ${ }^{2}$ Department of Orthopaedic and Traumatology, Faculty of Medicine, Universiti Kebangsaan Malaysia Medical Centre, Jalan Yaacob Latif, Bandar Tun Razak, 56000 Cheras, Kuala Lumpur, Malaysia.

${ }^{3}$ Faculty of Medicine and Sciences, Universiti Malaysia Sabah.

Background and aims: Scoliosis can have negative effects on the psychological well being and the quality of life of the patients. Adolescents were expected to have major concern over their appearance, thus being diagnosed with disfiguring conditions, as scoliosis would make them anxious, depressed and subsequently impact their quality of life. This study aimed to assess depression, anxiety and its relation to the quality of life among adolescent idiopathic scoliosis (AIS) patients in University Kebangsaan Malaysia Medical Centre (UKMMC).

Materials and methods: A cross-sectional study was conducted at Scoliosis Clinic UKMMC from May to September 2017, focusing on patient with AIS who underwent conservative treatment. They were evaluated using two selfadministered questionnaires: Depression Anxiety Stress Scale-21 (DASS-21) and Scoliosis Research Society-22 scale (SRS-22).

Results: A total of 49 participants had completed this study. Half of them were Malays (53.1\%) and majority were females (85.7\%). Around $22.4 \%(n=11)$ showed depressive and stress symptoms, while $53.1 \%(n=26)$ were anxious. Mean total SRS22 score was 4.0 (1.2). There was significant relationship between anxiety with pain and self-image as well as between stress and pain $(p<0.05)$.

Conclusion: Psychological aspect should not be neglected in treating AIS patients as they may have depression, anxiety and also low self-esteem, due to their physical condition.

Keywords: Psychological Distress, Self-Perception, Conservative Management, Life Satisfaction 


\title{
The Relaxed Education as a Driver for Gaining Health Knowledge and Healthy Behaviours Practice among Preschool Children
}

\author{
NUR NAZIRA S, RIZWAN AA, NUR AISYAH SM, MUHAMMAD \\ AMIR FI, MAZIAH AM \\ Department of Nursing, Faculty of Medicine, Universiti Kebangsaan Malaysia Medical \\ Centre, Jalan Yaacob Latif, Bandar Tun Razak, 56000 Cheras, Kuala Lumpur, Malaysia.
}

Background and aims: Obesity in children is likely to persist into adulthood and predisposes children to have diabetes, sleep apnoea and cardiovascular disease. Hence, this specific program namely, 'Prevention of Obesity Program, (Henceforth; MyPObes-PaF)' was developed to identify the effectiveness in preventing obesity among young children.

Materials and Methods: In this quasi-experimental study, two workplace kindergartens were randomized into intervention and control group. MyPObes$\mathrm{PaF}$ program was implemented as relaxed education approach in the intervention group, which consisted of dietary and physical activity module while for the control group, they followed the kindergarten's daily routine without this program being introduced. Pre and post-data by using observation and questionnaire of $24 \mathrm{hrs}$ activity physical and dietary recall diary were collected from the participants for over 3 months' period. The pre-data collection involved baseline data for results monitoring/evaluation. After the 3 months period, post-data collection was conducted using the same method.

Results: Observational result as evidenced in this quasi-experimental study showed increase in awareness towards healthy behaviour and gaining health knowledge in intervention group while there was no change in the control group. In particular, physical activity and food diaries showed improvement on healthy practice, which they preferred eating healthy and balanced diet as well as active and healthy in doing physical activity in interventions group compared to control group.

Conclusion: The relaxed education is proven as a driver for gaining health knowledge and healthy behaviours practice among preschool children. Indirectly it is evidence of the effectiveness of the implementation of MyPObes-PaF programme. Therefore it is recommended to be implemented in kindergarten's syllabus module as it is effective in providing health knowledge and practice on healthy behaviour as well as the relaxed education approach is the best suit to teach young children on health.

Keywords: Obesity, Physical Activity, Diet 


\title{
Lecturers' Written Feedback: An Assessment of Medical Students' Interpretation and Expectation
}

\author{
ZULFADLI M, NURUL RASYIDAH H, NURUL HIKMAH MR, \\ NURUL HAZWANI O, MOHAMMAD SHUKRI K, MOHD NASRI
}

$\mathrm{AB}$

\begin{abstract}
Department of Medical Education, Faculty of Medicine, Universiti Kebangsaan Malaysia Medical Centre, Jalan Yaacob Latif, Bandar Tun Razak, 56000 Cheras, Kuala Lumpur, Malaysia.
\end{abstract}

Background and aims: Written feedback provides an important platform for students to reflect their works. Therefore, it is crucial for the lecturers to give effective written feedback for students' future usability. This study assessed how lecturers give written feedback, and students' interpretation and expectation on said feedback.

Materials and methods: Qualitative study using thematic analysis was adopted in this study. Phase one of this study involved gathering 90 case write-ups via purposive sampling and later analysed using deductive analysis. From there, the second phase of this study was conducted. 24 undergraduate medical students of the National University of Malaysia (Universiti Kebangsaan Malaysia) were interviewed. The semi-structured interviews were then analysed and coded into several clusters and various themes were formulated by means of inductive analysis.

Results: Phase one (deductive analysis) of this study revealed lecturers often provide justification of marks for every assessment. Giving hope and opportunity of voice were the least provided; probably due to lecturers' tight schedule. Later in phase two (inductive analysis) of this study, students voiced out their interpretations of the feedback written on their assignments. Eight major themes were outlined: plan of improvement, clarity, justification of marks, self-efficacy, positive emotions, motivation, usability, and feedback on grammatical and technical accuracy. Their expectations were also analysed and put into six themes: verbal feedback, engagement, timeliness, justification of marks, clarity and motivation.

Conclusion: Exploring students' interpretation and expectation toward written feedback will enlighten lecturers' understanding in giving effective written feedback thus assure better learning outcome.

Keywords: Feedback, Qualitative, Students' Expectation, Students' Interpretation, Assessment 


\title{
Lower Extremity Strength and its Effect on Functional Mobility among Paediatric Acute Lymphoblastic Leukaemia Patients: A Single-Centre Study
}

\author{
ISYRAF RR, MUHAMMAD HAQIMI Z, RAZIMA NR, FATHIN \\ SYAHIRA R, FATIN R, HAMIDAH A, DORIS SCL \\ Department of Paediatrics, Faculty of Medicine, Universiti Kebangsaan Malaysia Medical \\ Centre, Jalan Yaacob Latif, Bandar Tun Razak, 56000 Cheras, Kuala Lumpur, Malaysia.
}

Background and aims: Advances in treatment of childhood acute lymphoblastic leukaemia (ALL) has led to significantly improved survival rate. However, disease or treatment-related toxicity could cause decreased muscle strength and thus, impair their mobility and activities of daily life (ADL).

Materials and methods: A case-control study was conducted at Paediatric Unit, Universiti Kebangsaan Malaysia Medical Centre to examine the lower extremity strength among the ALL patients. Controls were healthy children of age and gendermatched. Subjects were required to perform 3 tasks: 5-times-sit-to-stand test (5TSTS), Timed-up-and-go test (TUG) and Timed-up-and-down-stairs test (TUDS). The fastest time taken to complete each task was recorded. Parents' perception of the subjects' functional abilities in their mobility and ADL were evaluated using Paediatric Evaluation of Disability Inventory - Computer Adaptive Test (PEDI-CAT).

Results: A total of 40 patients and 40 healthy controls, aged 7 to 18 years, were recruited. Both groups comprised 22 (55\%) males and $18(45 \%)$ females. There was no significant difference in the demographic characteristics between both groups. For the ALL patients, median ages at diagnosis and at study entry were 6.37 years (IQR 4.26, 8.22) and 9.99 years (IQR 7.96, 12.41), respectively. Mean time taken to complete the 3 tasks were significantly longer among the ALL patients compared to the healthy controls $(p<0.005)$, indicating significant lower extremity weakness among the patients. By using the PEDI-CAT, the patients were found to have significantly poorer score compared to healthy controls, indicating significant restriction in their mobility and ADL. Factors such as gender, risk-group stratification, age at diagnosis and duration off treatment were not associated with the severity of the muscle weakness.

Conclusion: Our study demonstrated that paediatric ALL patients had significantly impaired lower extremity muscle strength causing limitation in their mobility and ADL.

Keywords: Acute Lymphoblastic Leukaemia, Paediatrics, Muscle Strength 


\title{
Is Knowledge and Awareness of Needle Stick Injury among Future Healthcare Providers Sufficient?
}

\author{
HAMZAH FH ${ }^{1}$, ZARITH NZ ${ }^{1}$, NAWAL SYAKIRAH AW ${ }^{1}$, NAJWA \\ KHAIRIAH S', KYLIE AE', IDA ZARINA Z'1, ROSNAH I².
}

${ }^{1}$ Department of Emergency Medicine, ${ }^{2}$ Department of Community Health, Faculty of Medicine, Universiti Kebangsaan Malaysia Medical Centre, Jalan Yaacob Latif, Bandar Tun Razak, 56000 Cheras, Kuala Lumpur, Malaysia.

Background and aims: Needle stick injuries (NSI) are an important occupational hazard for health care personnel as they form an important route for transmission of blood borne pathogens. Therefore, the knowledge and awareness of NSI among the healthcare personnel is critical. This study aimed to determine the level of knowledge and awareness among students from the Faculty of Medicine at Hospital Chancellor Tuanku Mukhriz (HCTM).

Materials and Methods: A cross-sectional study was conducted from May 2017 to September 2017 among medical, nursing and paramedic students of HCTM. A validated self-administered questionnaire was delivered via convenience sampling. One sample T test was used to analyse the data against the standard setting value.

Results: A total of 328 students participated. The mean age of respondents was $23.32 \pm 2.37$. The prevalence of NSI was $8.3 \%$ with majority having at least once $(85.2 \%)$ and mostly not reported (74.1\%). Paramedic students had significantly higher knowledge $(10.71 \pm 1.64, p<0.001)$ and awareness $(5.50 \pm 0.86, p<0.001)$ compared to standard setting. Nursing students also had significantly higher knowledge $(9.94 \pm 1.38, p<0.001)$ and awareness $(5.35 \pm 1.07, p<0.001)$ compared to standard setting. Meanwhile, medical students did not have a significant difference in knowledge $(9.95 \pm 1.39, p=0.589)$ but a significant difference in awareness $(5.87 \pm 1.03, p<0.001)$ compared to standard setting. However, there was no significant mean difference of knowledge $(F(2,324)=2.006, p=0.136)$ but a significant mean difference in awareness $(F(2,324)=8.708, p<0.001)$ between the groups. The main exposure for NSI was at medical posting $(77.8 \%)$ during procedure needle recapping $(70.4 \%)$ using hollow needle $(63 \%)$.

Conclusion: The results showed that the knowledge and awareness of NSI among future healthcare providers is sufficient. However, the prevalence of NSI cannot be ignored and further intervention is warranted.

Keywords: Knowledge, Awareness, Students, Needle Stick Injury, Cross-sectional study 


\title{
Outcome of Surgical Reconstructions in Pathological Fracture of the Humerus
}

\author{
CHRISILIA L, MUHAMMAD NAJIB AR, NUR SYA SYA AR, \\ AZWINA JR, NURUL NABILAH AA, NOR HAZLA MH, ABDUL \\ YAZID MK
}

Department of Orthopaedics, Faculty of Medicine, Universiti Kebangsaan Malaysia Medical Centre, Jalan Yaacob Latif, Bandar Tun Razak, 56000 Cheras, Kuala Lumpur, Malaysia.

Background and aims: Bone metastasis often presents late in cancer patients and induces a wide bone loss resulting in severe pain and loss of arm function. The aim of treating the patient is to reduce morbidity and to improve the quality of life in terminal patients.

Materials and methods: In our centre, eighteen operations for skeletal metastasis of humerus were performed between 2009 until 2017. We evaluated the survival of implant, survival rate of patients and complications that may arise from the surgery.

Results: The most common surgical procedure done was plating (14 patients) followed by nailing ( 2 patients) and hemiarthroplasty ( 2 patients). There was total of 5 patients who suffered post-operative complications. These include wrist drop (3 patients), surgical site infection (1 patient) and limited range of motion (1 patient). Out of 18 patients, $11.11 \%$ of patients had loosening of implant and $83.33 \%$ had their implants in-situ. Only 3 of the 18 patients were available for Musculoskeletal Tumour Society (MSTS) scoring assessment and their mean score was $84.44 \%$.

Conclusion: Surgical reconstruction has a good functional outcome in patients with pathological fracture of the humerus. Thus, surgical reconstruction should outlast the patients to prevent revision of surgery.

Keywords: Complications, Reconstructive Surgery, Humerus 


\title{
The Effects of Rutaceae Plant Extract (ADDX) on Renal Oxidative Stress, Renal Function and Histological Changes in Rats Fed with Heated Palm Oil
}

\author{
IUNE LI C ${ }^{1}$, ANIZA AB ${ }^{1}$, MOHAMAD ZARRIN A ${ }^{1}$, NADIAH L ${ }^{1}$, \\ NURUL HIDAYAH MI ${ }^{1}$, FADHLULLAH ZUHAIR JS ${ }^{1}$, NUR HANI \\ $S^{1}$, SURIA HAYATI MP², KAMISAH Y', QODRIYAH HMS', NUR \\ AZLINA MF ${ }^{1}$, NORLIANA $M^{1}$ \\ ${ }^{1}$ Department of Pharmacology, ${ }^{2}$ Department of Pathology, Faculty of Medicine, Universiti \\ Kebangsaan Malaysia Medical Centre, Jalan Yaacob Latif, Bandar Tun Razak, 56000 \\ Cheras, Kuala Lumpur, Malaysia.
}

Background and aims: Prolonged consumption of heated palm oil causes detrimental effects on cardiovascular system, liver and kidneys. The detrimental effects of heated oils are associated with oxidative stress; hence the role of antioxidants in attenuating heated oil-induced effects has been widely studied. The aim of the present study was to determine the effects of polyphenol-rich Rutaceae plant extract (ADDX) on renal oxidative stress parameters, renal function and histological changes in rats fed with heated palm oil.

Materials and methods: Fifty-six male Sprague-Dawley rats $(n=56)$ were divided into seven groups. Control group was given normal rat chow, while other groups were fed with palm oil-enriched diet $(15 \% \mathrm{w} / \mathrm{w})$ of either fresh palm oil (FPO), fivetime-heated (5HPO) or ten-time-heated (10HPO); with or without the addition of ADDX $(0.15 \%, w / w)$ supplementation. After 16 weeks, the rats were sacrificed and the kidneys were harvested for analysis. Total phenolic content (TPC) of ADDX was determined via the Folin-Ciocalteu assay.

Results: ADDX supplementation improved heated palm oil-induced oxidative stress parameters in the kidneys, shown by reduced levels of renal thiobarbituric acid (TBARS) and renal Nicotinamide adenine dinucleotide phosphate (NADPH) oxidase in 5HPO and 10HPO groups. Renal haem oxygenase levels were increased with ADDX supplementation in the heated oil groups. Decreased serum creatinine was observed in 5HPO group with ADDX supplementation, but not in $10 \mathrm{HPO}$ group. Heated oil caused mild interstitial inflammation with vascular congestion in $5 \mathrm{HPO}$ and $5 \mathrm{HPO}+\mathrm{ADDX}$ groups, while $10 \mathrm{HPO}$ group had moderate inflammation and vascular congestion. ADDX supplementation in 10HPO group was able to reduce these changes as only mild interstitial inflammation and congestion was observed. The TPC of ADDX was $64.3 \pm 14.3 \mathrm{mg} / \mathrm{g}$ of gallic acid equivalent (GAE). 
Conclusion: ADDX has a potential to reduce renal oxidative stress parameters, improve renal function and reduce renal inflammation possibly mediated via its antioxidant properties.

Keywords: Rutaceae, Oxidative stress, Heated oil 


\title{
Knowledge and Perception Towards Supplementary Immunization Activity among Mothers in Cheras, Kuala Lumpur
}

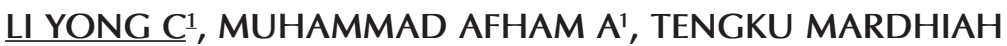 \\ TN' ${ }^{1}$, NURUL NAJWA AR ${ }^{1}$, WAN NUR ALYA WA' ${ }^{1}$, NAZARUDIN S1, \\ NORIAH H ${ }^{2}$, MOHD ROHAIZAT H ${ }^{1}$
}

\begin{abstract}
${ }^{1}$ Department of Community Health, Faculty of Medicine, Universiti Kebangsaan Malaysia Medical Centre, Jalan Yaacob Latif, Bandar Tun Razak, 56000 Cheras, Kuala Lumpur, Malaysia.

${ }^{2}$ Cheras Health Office, Jalan Yaacob Latiff, 56000 Cheras, Kuala Lumpur, Malaysia.
\end{abstract}

Background and aims: Among the main reasons for re-emergence of vaccine preventable diseases were missed or incomplete immunization schedule. The supplementary immunization activity (SIA) is an important intervention done to provide complete immunization coverage among those children. Better outcome came along with good knowledge and perception on the program. Thus this study aimed to assess the level of knowledge and perception of the mothers towards SIA program.

Materials and methods: This was a cross-sectional study conducted among mothers with children $\leq 15$ years old in Cheras, Kuala Lumpur. Data was collected by interview, using the guided questionnaire, which consists of four sections to assess the socio demographic, socio economic, knowledge and perception regarding SIA. The questionnaire was validated for internal consistency with Cronbach's alpha 0.461 for knowledge and 0.729 for perception.

Results: There were 105 respondents with the median age of 33 years (IQR: 28-38) with majority of them being Malays (82.9\%), Muslims (83.8\%), married $(97.1 \%)$ and $(57.1 \%)$ with 1-2 children in the family. Half of them were from low-income family $(46.7 \%)$ and had secondary education level (54.3\%) and were housewives (47.6\%). One third of the respondents (33\%) never heard about SIA before. Overall had poor knowledge (82.9\%) and perception (95.2\%) towards SIA. There is a significant association between the level of knowledge on SIA with household income $\left(\chi^{2}=7.746, p=0.019\right)$ and occupation $\left(\chi^{2}=6.457, p<0.05\right)$. However, there was no significant association between the socio-demographic and socio-economic factors and perception towards SIA.

Conclusion: The knowledge and perception among mothers on SIA are still poor. More intensive health educations may be useful to be incorporated within the program implementation to increase the community understanding and perception towards SIA in the future.

Keywords: Knowledge, Perception, Mass Immunization, Kuala Lumpur. 


\title{
Parental Perception of Emotional and Behavioral Problems among Aborigine and Non-Aborigine Children and Parenting Stress in Kampung Sungai Buah
}

\author{
MUHAMAD FAREZ FMA, WEI XIU H, AZLEEN AUNIE RZ, NUR \\ ZAIREEN MZ, MAS ANIZA MB, FAIRUZ NAZRI AR, SHALISAH S.
}

Department of Psychiatry, Faculty of Medicine, Universiti Kebangsaan Malaysia Medical Centre, Jalan Yaacob Latif, Bandar Tun Razak, 56000 Cheras, Kuala Lumpur, Malaysia.

Background and aims: Aborigine people also known as 'Orang Asli' (OA), are a minority group in Malaysia and there are not many studies that have been done on them especially in view of their mental health, recently. The purpose of this study was to determine the parental perception of behavioural and emotional problems in $\mathrm{OA}$ and non-aborigine (NA) children in Kampung Sungai Buah, Bangi and its association with parenting stress in both communities.

Materials and Methods: This was a cross-sectional comparative community study. A total of 27 respondents from OA and 39 from NA were involved and required to answer demographic questionnaire, Strength and Difficulty Questionnaire (SDQ) and Parent Stress Index (PSI). Different sampling methods were used due to limited sample size. All data were analysed by using Statistical Package for the Social Sciences (SPSS) version 20.0.

Results: OA children had higher total SDQ score than NA children $(p=0.010)$. Non-OA children had higher conduct problem than OA children $(p=0.005)$. NA fathers had higher parental distress than OA fathers $(p=0.02)$. There was negatively moderate correlation between total SDQ and total PSI scores between OA and NA population.

Conclusion: $\mathrm{OA}$ and NA had distinct parent-child problems in their own populations. Adequate support should be given to them. OA had strengths in their rearing practices, which leads to lower conduct problems in their children. Further studies should be conducted in terms of parenting style, environment, lifestyle in OA through qualitative approach that might provide more information on how to manage problematic parent-child problem.

Keywords: Parents, Children, Mental Health, Aborigine, Malaysia 


\title{
Prevalence of Sepsis in Community-Acquired Infections in Medical Wards Using Sepsis-3 Definition
}

\author{
MOHAMAD IRSYADUDDIN HMY, NUR ARINA I, SIEW LING L, \\ NOR ATHIRA M, NORSYUHADAH A, TIDI MAHARANI H.
}

Department of Medicine, Faculty of Medicine, Universiti Kebangsaan Malaysia Medical Centre, Jalan Yaacob Latif, Bandar Tun Razak, 56000 Cheras, Kuala Lumpur, Malaysia.

Background and aims: The new Sepsis-3 definition, defined sepsis as an increase of two points or more in the Sequential Organ Failure Assessment (SOFA) score. For patients with infection, an increase of two SOFA points is associated with an overall mortality rate of $10 \%$. To date, there has been no study examining the prevalence of sepsis using the new definition in Malaysia.

Materials and methods: A prospective cohort study was conducted for two months in six medical wards in Universiti Kebangsaan Malaysia Medical Centre. Subjects aged 18 years and above with suspected or diagnosed with communityacquired infection were screened for sepsis using the Sepsis-3 definition.

Results: A total of 175 patients were admitted for community-acquired infection. One hundred and fifty-four cases (88\%) were found to have an increased SOFA score of 2 or more. However, 100 patients had co-morbidities such as chronic kidney disease (CKD) and diabetes mellitus (DM) in which baseline SOFA could not be accurately determined. Seventy-five of these cases had a baseline SOFA score of 0 and 35 cases $(47 \%)$ were clinically diagnosed as true sepsis. There were no differences in the length of stay in sepsis vs. non-sepsis group (5.78 \pm 3.389 and 6.60 $\pm 2.547, p=0.469)$. There were also no differences in mortality between subjects with sepsis vs. non-sepsis ( $p>0.05)$.

Conclusion: In this single institution study, the new Sepsis-3 definition was not a good indicator in predicting the length of stay and mortality of the patients. However, it was a sensitive tool to determine the prevalence of sepsis. Limitations of these new criteria include the inability to correctly diagnose baseline SOFA in those with pre-morbid diseases such as CKD and DM.

Keywords: Organ Failure, Sepsis, Mortality, Stay 


\title{
Evaluation of Factors That Influence Prolonged Emergency Department Stay among Admitted Patients in Universiti Kebangsaan Malaysia Medical Centre
}

\author{
AHMAD HANIF I, ADILA SYAFIQAH AA, CHEE LING E, SITI NOR \\ AS, SITI NOREZAN S, NIK AZLAN NM. \\ Department of Emergency Medicine, Faculty of Medicine, Universiti Kebangsaan \\ Malaysia Medical Centre, Jalan Yaacob Latif, Bandar Tun Razak, 56000 Cheras, Kuala \\ Lumpur, Malaysia.
}

Background and aims: Emergency department (ED) stay is defined as the period seen by ED doctors to the time of ward admission. In this study, prolonged ED stay is the length of stay (LOS) for more than 6 hours. This study was carried out to assess the factors influencing prolonged ED stay among admitted patients in Universiti Kebangsaan Malaysia Medical Centre (UKMMC).

Materials and methods: Data was collected retrospectively from medical records. A total of 662 cases of admission to the ward through ED were taken from $1^{\text {st }}$ January 2016 to $30^{\text {th }}$ June 2016 in UKMMC. Patients with incomplete data and those admitted through outpatient clinic and Patient Admission Centre (PAC) were excluded.

Results: The median length of stay in ED was 6 hours. There were 280 (42.3\%) patients with prolonged ED LOS. Medical department had the maximum median and paediatrics department had the minimum median ED LOS which were 8 hours and 3 hours, respectively. The median referral time for patient with prolonged ED stay was 2 hours and 39 minutes, whereas for patient with ED stay of less than 6 hour was 1 hour and 35 minutes. A total of 31 patients (4.68\%) out of 662 patients required ICU admissions. Among these, 21 (67.74\%) patients had prolonged ED stay. The average bed occupancy rate (BOR) per month and average rate of admission per day ranging from $61.22 \%$ to $65.24 \%$ and from $33.2 \%$ to $40.3 \%$ respectively, which remained plateau throughout the study period.

Conclusion: Two independent factors were found to be the major reasons for prolonged ED length of stay namely the type of specialty involved and lack of inpatient bed. The result of this study serves as the basis for further research to minimise ED LOS.

Keywords: Bed Occupancy, Patient Admissions, Delay, Emergency Medicine 


\title{
Family Impact of Having a Child with Autism Spectrum Disorder: A Comparison Between Fathers and Mothers
}

\author{
AKMAL HAYAT AK, ASTRID JLO, ERMA SYAFIRA Z, NURUL \\ WAHIDA K, SYAMIM AMIRA S, JURIZA I, WAI WAI Y \\ Department of Paediatrics, Faculty of Medicine, Universiti Kebangsaan Malaysia Medical \\ Centre, Jalan Yaacob Latif, Bandar Tun Razak, 56000 Cheras, Kuala Lumpur, Malaysia.
}

Background and aims: Raising a child with Autism Spectrum Disorder (ASD) presents numerous challenges to parents. It is important to examine how these challenges impact family life for better understanding of clinicians towards needs of parents. This research aimed to compare the impact of having a child with ASD on both parents' Total Family Impact scores, health-related quality of life (HRQoL) and family functioning.

Materials and methods: In this cross-sectional study, both parents of 80 children with ASD currently attending Child Developmental Centre, in Universiti Kebangsaan Malaysia Medical Centre, were recruited to participate in a selfadministered questionnaire study. Questionnaires pack on family background and PedsQL ${ }^{\mathrm{TM}}$ Family Impact Module were distributed once consent was obtained. Completed questionnaires were returned either in person or by post. Paired samples T-test were conducted to analyse statistical differences between fathers' and mothers' perception of family impact using SPSS version 22.0.

Results: A response rate of $46.3 \%$ was recorded as only 37 sets of completed questionnaires were received. Overall, parental ratings were lower than previous studies on children with disabilities. Nonetheless, there were significant difference in the Total Family Impact scores for fathers $(68.19 \pm 17.89)$ and mothers $(62.11 \pm 18.18)$, $p=0.041$, as well as Family Functioning scores for fathers (71.03 \pm 21.52 ) and mothers (61.82 \pm 21.06$), p=0.008$. There was no significant differences in HRQoL scores for fathers $(71.22 \pm 18.01)$ and mothers $(66.08 \pm 20.24), p=0.133$. These results suggest that both parents experienced impact on their family with mothers experiencing more overall family impact and poorer family functioning than father.

Conclusion: Both parents need holistic support in managing their child for better functioning of life.

Keywords: Autism, Parents, Family Impact, Quality of Life, Family Functioning 


\title{
The Level of Caregiving Knowledge and Self-Efficacy among Caregivers of Stroke Patient
}

\author{
FATHIN ALYAA MF, MAY YIN H, NUR KHAIRINA I, NUR SARAH \\ AISYAH A, CHAI ENG T, AZNIDA FIRZAH AA. \\ Department of Family Medicine, Faculty of Medicine, Universiti Kebangsaan Malaysia \\ Medical Centre, Jalan Yaacob Latif, Bandar Tun Razak, 56000 Cheras, Kuala Lumpur, \\ Malaysia.
}

Background and aims: Family caregivers of stroke patients provide care for activities of daily living. Unfortunately, most do not receive adequate prior preparation or training. This study aimed to determine levels of care-giving knowledge and selfefficacy among caregivers of stroke patients.

Materials and methods: This cross-sectional study was conducted in the Department of Medical Rehabilitation Services of an urban teaching hospital involving 128 caregivers of stroke patients. The caregivers were conveniently sampled and interviewer assisted them to complete the data collection form including socio-demographic data, functional status, Family Caregivers Activation Transition tool (FCAT) and a newly validated Care-giving Knowledge Questionnaire (CKQ). FCAT measured the level of self-efficacy, whereas CKQ measured caregivers' knowledge regarding positioning and feeding. Descriptive and bivariate inferential statistics were used for data analysis.

Results: Among the caregivers sampled, $87.3 \%$ had poor knowledge on positioning (mean score 14.9 \pm 4.32 ) whereas $91.2 \%$ had good knowledge on feeding (mean score 13.3 \pm 1.70$)$. Mean score for FCAT was 49.7 \pm 6.0 . Caregivers' self-efficacy were associated with age $(r=0.337, p<0.001)$. Self-efficacy of caregivers was also associated with marital status $(\mathrm{F}=6.423, \mathrm{p}=0.002)$, caregiver status $(\mathrm{t}=2.083$, $\mathrm{p}=0.038)$, education $(\mathrm{F}=3.11, \mathrm{p}=0.048)$, training received $(\mathrm{t}=2.673, \mathrm{p}=0.009)$ and duration of care-giving $(\mathrm{F}=3.586, \mathrm{p}=0.031)$.

Conclusion: Caregivers' knowledge on positioning of stroke patients was poor. Intervention programs and training for caregivers of stroke are recommended to improve caregivers' self-efficacy.

Keywords: Stroke, Caregiver, Self-Efficacy, Knowledge 


\title{
Retrospective Study of Association between Computed Tomography (CT) Imaging Findings and Event Free Survival Rate among Paediatric Lymphoma
}

\author{
MOHD AL-HAFIZ K' ${ }^{1}$, AMIRA SAKINAH S', SCHE PHEI G', NOOR \\ SHAHILA S', NURUL SYUHADA S', FAIZAH MZ1, C-KHAI L². \\ ${ }^{1}$ Department of Radiology, ${ }^{2}$ Department of Paediatrics, Faculty of Medicine, Universiti \\ Kebangsaan Malaysia Medical Centre, Jalan Yaacob Latif, Bandar Tun Razak, 56000 \\ Cheras, Kuala Lumpur, Malaysia.
}

Background and aims: Lymphoma is one of the leading cancers in the world and increasing trend in Malaysia. The main aim of the study was to evaluate the association between computed tomography (CT) findings at presentation and event free survival rate among paediatric lymphoma.

Materials and methods: Thirty-one paediatric patients, below 18 years, who were diagnosed as Hodgkin Lymphoma and Non-Hodgkin Lymphoma, were included in the study, which was conducted from April 2017 to August 2017 in the Radiology Department, Universiti Kebangsaan Malaysia Medical Centre. Patient CT imaging, demographic data and survival status of patient at 1-year, were obtained from the medical record unit and lymphoma database from paediatric department. CT findings were classified into location, solitary or multiple organ involvement, lesion attenuation relative to muscle, lesion homogeneity, presence of calcification, necrosis and local infiltration. Chi-square statistical analysis was done to assess the association between $\mathrm{CT}$ findings with event free survival.

Results: Out of 31 patients, there were 28 males and 3 females, who were diagnosed with Hodgkin Lymphoma and Non-Hodgkin Lymphoma $(40 \%$ and $60 \%$ of cases respectively). CT findings of lymphomatous lesions demonstrated nodal only involvement in 50\%, extra-nodal in $16.7 \%$ and $33.3 \%$ involved both. Solitary and multiple organ involvement were $46.7 \%$ and $53.3 \%$ respectively. Majority of lesions were hypo-dense (43.3\%), homogeneous (63.3\%) and showed local infiltration $(66.7 \%)$, while few cases showed necrosis $(16.7 \%)$ and none show calcification. Higher event free survival after 1 year (EFS24months) was seen with nodal involvement $(100 \%)$, while patient with extra-nodal involvement had mortality and recurrence in $60 \%$, which was statistically significant $(p<0.05)$.

Conclusion: The majority of lymphoma type was Non-Hodgkin lymphoma and male children. Variable distribution and appearance of lesions were seen on CT with patients who had extra-nodal involvement demonstrated statistically significant low event free survival than nodal involvement.

Keywords: Hodgkin, Extranodal, Radiography, Survival, Paediatrics 


\title{
Prevalence of Irritable Bowel Syndrome in an Urban Multi-Racial Population
}

\author{
NUR ADILAH R ${ }^{1}$, ATIF ZIMAM Z ${ }^{1}$, NUR FAREEHAH AB ${ }^{1}$, NUR \\ ADILAH CG ${ }^{1}$, CHAI SOON N², ZHIQIN W², RAJA AFFENDI RA², \\ NORFILZA MM ${ }^{1}$
}

${ }^{1}$ Department of Physiology, ${ }^{2}$ Gastroenterology Unit, Department of Medicine, Faculty of Medicine, Universiti Kebangsaan Malaysia Medical Centre, Jalan Yaacob Latif, Bandar Tun Razak, 56000 Cheras, Kuala Lumpur, Malaysia.

Background and aims: Irritable bowel syndrome (IBS) is a functional gastrointestinal disorder characterised by abdominal pain and change in the bowel habit without structural abnormalities. Its prevalence is less common among Asian as compared to Western population. In Malaysia, the prevalence of IBS in multi-racial urban population is unknown. This present study is aimed to determine the prevalence of IBS at the tertiary centre that covers multi-racial population in Cheras, Kuala Lumpur using Rome III diagnostic criteria.

Materials and Methods: Random sampling method was used to obtain the targeted samples. Patients or relatives attending the outpatient gastroenterology clinics and Endoscopy Centre, Universiti Kebangsaan Malaysia Medical Centre were recruited. Individuals aged 18 to 81 years, who fulfilled the inclusion criteria and exclusion criteria were included. Pre-validated Malay, Chinese and English versions of Rome III Irritable Bowel Syndrome Module Questionnaire was used for the evaluation of prevalence of IBS.

Results: Overall, we recruited 502 respondents and identified 53 (10.6\%) of them having IBS. Among the IBS subjects, 35.8\% were men whereas $64.2 \%$ were women. The mean age for IBS was $36.6 \pm 15$ years as compared to $37.6 \pm 14$ years in non-IBS respondents. The commonest subtype of IBS was mixed-type (51.9\%), followed by diarrhoea-predominant $(22.2 \%)$, constipation-predominant $(14.8 \%)$ and unspecified-type (11.1\%). The majority of patients were among the Malays $(69.8 \%)$ followed by Indians (17\%) and Chinese (13.2\%). IBS was observed among those who are non-smokers; do not consume alcohol and low household income individuals although it was not statistically significant as compared to the non-IBS respondents.

Conclusion: This study revealed that the prevalence of irritable bowel syndrome among multi-racial urban population was $10.6 \%$. Majority of patients were young women in mid-thirties and the IBS- mixed was the predominant subtype.

Keywords: Functional Gastrointestinal Disorder, Digestive System Diseases, Malaysia, Ethnic Group, Epidemiology 


\title{
Establishing an Animal Model of Osteoporosis Due to Secondary Hypogonadism in Male Rats
}

\author{
KRYSTINE MT ${ }^{1}$, NUR-VAIZURA ${ }^{1}{ }^{1}$, MUHAMMAD AFIQ ACZ \\ NORAIN Z1 ${ }^{1}$ NUR QURAISHA S', NURUL AMNI MR', IMA- \\ NIRWANA $S^{1}$, NOR AINI J ${ }^{2}$, KOK-YONG $C^{1}$
}

\begin{abstract}
'Department of Pharmacology, Faculty of Medicine, Universiti Kebangsaan Malaysia Medical Centre, Jalan Yaacob Latif, Bandar Tun Razak, 56000 Cheras, Kuala Lumpur, Malaysia.

${ }^{2}$ School of Healthcare Sciences, Faculty of Health Science, Universiti Kebangsaan Malaysia Medical Centre.
\end{abstract}

Background and aims: The current preferred animal model of osteoporosis induced by testosterone deficiency was the orchiectomized model, which mimicked primary hypogonadism in men. Animal osteoporosis model due to secondary hypogonadism was less characterized. This study aimed to establish an animal model of male osteoporosis due to secondary hypogonadism using buserelin, a gonadotropin-releasing hormone agonist.

Materials and Methods: Three-month-old Sprague-Dawley rats $(n=46)$ were randomly assigned into three experimental arms consisting of baseline $(n=6)$, orchiectomy $(n=16)$ and buserelin arms $(n=24)$. The baseline arm $(n=6)$ was sacrificed upon receipt. The orchiectomy arm was divided into sham-operated $(n=8)$ and orchiectomized groups $(n=8)$. The buserelin arm was divided into three groups ( $n=8$ per group), i.e. normal control group $(n=8)$ and buserelin groups treated with buserelin at dose $25 \mu \mathrm{g} / \mathrm{kg}(\mathrm{n}=8)$ or $75 \mu \mathrm{g} / \mathrm{kg}(\mathrm{n}=8)$ for three months. After three months, all rats were sacrificed. The blood was collected for circulating testosterone analysis. The bones were harvested for biomechanical analysis and bone calcium content estimation.

Results: Testosterone deficiency was induced by orchiectomy and both doses of buserelin $(p<0.05)$. Displacement and strain of the bone was decreased by buserelin $25 \mu \mathrm{g} / \mathrm{kg}(p<0.05)$ but not orchiectomy ( $p>0.05)$. Both orchiectomy and buserelin did not influence bone calcium level in male rats $(p>0.05)$ after three months.

Conclusion: Buserelin caused significant reduction in bone biomechanical strength in male rats, thus it can be used in animal osteoporosis model due to secondary hypogonadism. A longer time may be needed for buserelin to exert its effect on bone calcium level.

Keywords: Androgen, Bone, Buserelin, Osteopenia, Testosterone 


\section{Prevalence of Vitamin D Deficiency and its Associated Risk Factors among Women in Early Pregnancy at Tertiary Medical Centre in Kuala Lumpur}

\section{FATIN NORHAFIZAH F' ${ }^{1}$ MUHAMMAD AZFAR SMA ${ }^{1}$, NURSABRINA MY', NURUL SYAHIDA J', POH VIEN G ${ }^{1}$, KOK-YONG ${ }^{2}$, RAHANA AR ${ }^{1}$, NOR HASLINDA AA ${ }^{1}$}

${ }^{1}$ Department of Obstetrics and Gynaecology, ${ }^{2}$ Department of Pharmacology, Faculty of Medicine, Universiti Kebangsaan Malaysia Medical Centre, Jalan Yaacob Latif, Bandar Tun Razak, 56000 Cheras, Kuala Lumpur, Malaysia.

Background and aims: Vitamin D deficiency [25-hydroxyvitamin D $<50 \mathrm{nmol} / \mathrm{L}$ ] is a major health problem worldwide which affects pregnant women despite living in sun-rich countries. Maternal vitamin D deficiency could affect both mother and foetus. Hence, this study aimed to determine serum vitamin D status among women in early pregnancy and investigate the associated risk factors.

Materials and methods: A cross-sectional study was carried out among 57 pregnant women in early pregnancy at tertiary medical centre in Kuala Lumpur. The subjects answered physician guided questionnaire consisting of demographic information, clinical data, validated food frequency questionnaire, sun protection score and duration of exposure to sunlight. Skin colour was assessed by using Fitzpatrick classification. Serum from blood samples of pregnant women at 11-16 weeks were isolated and analysed using ELISA to determine 25-hydroxyvitamin D level.

Results: The mean age of respondents was $32.88 \pm 4.52$ years. Most participants were Malay (85.96\%) and $14.04 \%$ were non-Malay. Vitamin D deficiency among women at early pregnancy seen in our cohort had similar findings (91.23\%) with previous studies in Malaysia. There were no association between risk factors with vitamin $D$ status such as working status $(p=1.00)$, intake of vitamin $D$ in dietary $(\mathrm{IU} /$ day) $(p=0.90)$, skin colour $(p=0.42)$, dressing style $(p=0.22)$ and duration of sun exposure $(p=0.09)$. However, further analysis on intake of vitamin $D$ in dietary significantly showed that respondents who took supplements containing vitamin $\mathrm{D}$ had higher total vitamin $D$ intake per day $(p=0.001)$. Other dietary habits showed no significant contribution to respondents' vitamin $\mathrm{D}$ intake per day.

Conclusion: Prevalence of vitamin D deficiency was high among urban Malaysian women in early pregnancy. There were no association between risk factors and vitamin D status. Consuming supplements containing vitamin D in early pregnancy could improve the vitamin D level of these vitamin D deficient women.

Keywords: Supplement, 25-Hydroxyvitamin D, Occupation, Dietary Intake, Sun Exposure 


\title{
Incidence of Hypoglycaemic Events and Weight Gain and Their Relationships with Insulin Adherence among Insulin-Treated Diabetic Patients in Universiti Kebangsaan Malaysia Medical Centre
}

\author{
MUHAMMAD DHIRAR MD, LAILATUL SYAHIRAH I, ESTHER HII \\ CX, SITI NURSYAFIQAH MR, SITI AISYAH A, AISHAIRMA A.
}

Department of Nursing, Faculty of Medicine, Universiti Kebangsaan Malaysia Medical Centre, Jalan Yaacob Latif, Bandar Tun Razak, 56000 Cheras, Kuala Lumpur, Malaysia.

Background and aims: Insulin adherence level is poor despite its importance for glycaemic control due to insulin side effect of hypoglycaemia and weight gain. However, this knowledge is lacking for Malaysian population. The aim of this study was to investigate the incidence of hypoglycaemic events and weight gain in relation to insulin adherence in insulin-treated patients with diabetes in Universiti Kebangsaan Malaysia Medical Centre.

Materials and Methods: The study was conducted cross-sectionally on 162 insulin-treated patients with diabetes at Klinik Primer, UKMMC. Data were collected using a questionnaire; hypoglycaemic events and weight gain were measured by asking whether the patients had these experiences and if yes, they were asked the frequency of the hypoglycaemic events and the total weight gain was calculated, insulin adherence was measured using Malaysian Medication Adherence Scale (MALMAS). Data were analysed using Spearman correlation, Mann-Whitney and Kruskal-Wallis test in Statistical Package for the Social Sciences (SPSS) version 22.

Results: Patients' mean age was 63 years (SD 9.4). Majority of them were Malays $(54.9 \%)$, females $(51.2 \%)$, married $(91.4 \%)$ and had educational level of secondary school (45.1\%) while all had type 2 diabetes mellitus with an average duration of almost 14.9 years (SD 8.6) and HbA1c $8.38 \%$ (SD 1.69). Experience of hypoglycaemic events and weight gain were reported by $43.2 \%$ (frequency of hypogylcaemic events: Mean $=3.43 \pm 9.73$ ) and $25.3 \%$ (total weight gain: Mean=1.41 \pm 2.86 ) of the patients, respectively. The insulin adherence was found significantly related to the patients ${ }^{\prime}$ age (rho $\left.=0.231, \mathrm{p}=0.003\right)$ and $\mathrm{HbA1c}(\mathrm{rho}=-0.261, \mathrm{p}=0.001)$ only.

Conclusion: Age and $\mathrm{HbA1c}$ level were significantly related to insulin adherence but not the hypoglycaemic events and the weight gain. Further studies investigating other factors that affect insulin adherence in insulin-treated patients with diabetes is warranted.

Keywords: Diabetes mellitus, Insulin, Adherence, Hypoglycaemic, Weight gain 


\title{
Clinico-Epidemiology and Anti-Microbial Susceptibility Pattern of Non-Typhoidal Salmonellosis in Universiti Kebangsaan Malaysia Medical Centre
}

\author{
CHOONG YS, SYAZWAN A, MOHAINY MW, FATIN ALIA RJ, \\ NURHASYIMA MN, ZALINA I, RAMLIZA R \\ Department of Microbiology and Immunology, Faculty of Medicine, Universiti \\ Kebangsaan Malaysia Medical Centre, Jalan Yaacob Latif, Bandar Tun Razak, 56000 \\ Cheras, Kuala Lumpur, Malaysia.
}

Background and aims: Non-typhoidal salmonellosis has been a major cause of diarrhoea worldwide, with Salmonella enteritidis as the commonest serotype in Malaysia. The aim of this study was to determine the clinico-epidemiological data and anti-microbial susceptibility pattern of non-typhoidal salmonellosis in Universiti Kebangsaan Malaysia Medical Centre (UKMMC).

Materials and methods: Salmonella spp. serotyping report was obtained from Institute for Medical Research (IMR) after being isolated in Bacteriology Laboratory, Department of Diagnostic Laboratory Service in UKMMC. Demographic and clinical data of patients were retrieved from medical records in Health Information Department. Thereafter, data was analysed by using descriptive statistics and the Chi-squared test.

Results: There were 268 cases of Salmonella spp. identified. However, only 229 cases were non-typhoidal Salmonella spp. and antibiotic susceptibility pattern identified. Salmonella enteritidis (52\%) was the commonest serotype, followed by Salmonella typhimurium (11.8\%) and Salmonella weltevreden (7.9\%). Ceftriaxone $(94.8 \%)$ was the most susceptible antibiotic, followed by amoxicillin-clavulanate (91.5\%). Ciprofloxacin susceptibility was only 67\%. However, only 176 cases were being analysed for clinico-epidemiology data. The most common clinical manifestations were fever (75.6\%), diarrhoea (65.4\%) and vomiting (39.2\%). Meanwhile, main age groups affected were middle-aged group (23.9\%) and elderly (21.6\%).

Conclusion: From this study, the triad of fever, diarrhoea and vomiting should raise the index of suspicion of non-typhoidal salmonellosis as a differential diagnosis. Ceftriaxone was the antibiotic of choice for empirical treatment for non-typhoidal salmonellosis.

Keywords: Diarrhoea, Antibiotic resistance, Salmonella, Serotype, Ciprofloxacin 


\title{
Species Distribution and Antifungal Susceptibility Patterns of Aspergillus Spp. at Universiti Kebangsaan Malaysia Medical Centre
}

\author{
AFIQAH NAJWA R, NORA AZYAN $M$, AHMAD FITRI K, FUZLA \\ AIZAHANI MS, WINNIE JIAU XH, TZAR MOHD NK. \\ Department of Medical Microbiology and Immunology, Faculty of Medicine, Universiti \\ Kebangsaan Malaysia Medical Centre, Jalan Yaacob Latif, Bandar Tun Razak, 56000 \\ Cheras, Kuala Lumpur, Malaysia.
}

Background and aims: Species of aspergillus are medically important as they can cause a range of disease to humans such as infection to external ear, skin lesions, abdomen, chest wall and ulcers. The aim of our research was to determine the species distribution and antifungal susceptibility patterns of Aspergillus spp. in Universiti Kebangsaan Malaysia Medical Centre.

Materials and methods: In this prospective study, 30 Aspergillus spp. isolate were collected from cultures of clinical specimens from November 2016 onwards. The moulds were identified by observing colony morphologies on Sabouraud dextrose agar, while the antifungal susceptibility testing was performed using Sensititre YeastOne YO10 broth microdilution method. Antifungal agents tested include amphotericin B, fluconazole, itraconazole, voriconazole, posaconazole, anidulafungin, caspofungin, micafungin and flucytosine.

Results: Out of 30 Aspergillus spp. isolates, 19 (63.3\%) were A. niger, 7 (23.3\%) were $A$. fumigatus, $3(10.0 \%)$ were $A$. flavus and $1(3.3 \%)$ were $A$. nidulans. General susceptibility pattern for $A$. niger showed Micafungins had the lowest minimum effective concentration (MEC) 0.008-0.03 g/mL, whereas Amphotericin B had the highest minimum inhibitory concentration (MIC) $0.5-2 \mathrm{~g} / \mathrm{mL}$.

Conclusion: Although, most Aspergillus spp. isolates were susceptible to the antifungals being tested, resistance to several drugs such as azoles and echinocandins has been increasing in recent years.

Keywords: Echinocandins, Azoles, Minimum Inhibitory Concentration, Moulds, Aspergillus 


\title{
Mild to Moderate Carpal Tunnel Syndrome: Does Pulsed Short Wave Diathermy Have Better Efficacy Than Transcutaneous Electrical Nerve Stimulation?
}

\author{
WAZIR AIMAN MAW' ${ }^{1}$, VINAYAGI SELVAM ${ }^{1}$, FARAH HANISAH \\ MS ${ }^{1}$, SHARAH ENGAL' ${ }^{1}$ NURUL JANNAH $Z^{1}$, BRENDA SARIA \\ Y, ${ }^{1}$ RASHIDAH HI ${ }^{1}$, AMARAMALAR SELVI NS ${ }^{1}$, SHALIMAR \\ ABDULLAH ${ }^{1}$, JAMARI SAPUAN' ${ }^{1}$, MANIMALAR SELVI NS² \\ ${ }^{1}$ Department of Orthopaedics \& Traumatology, Faculty of Medicine, Universiti \\ Kebangsaan Malaysia Medical Centre, Jalan Yaacob Latif, Bandar Tun Razak, 56000 \\ Cheras, Kuala Lumpur, Malaysia. \\ ${ }^{2}$ Department of Pathology, Faculty of Medicine, University of Malaya.
}

Background and aims: Short-Wave Diathermy has proved efficacious than other non-surgical treatments in treating various musculoskeletal diseases. However, its efficacy remains unestablished in treating Carpal Tunnel Syndrome (CTS). This study aimed to compare the effectiveness of Pulsed Short-Wave Diathermy (PSWD) versus Transcutaneous Electrical Nerve Stimulation (TENS) in the treatment of mild to moderate CTS.

Materials and methods: A prospective comparative interventional study was conducted at a University Hospital in Malaysia between April and July 2017. This study involved 16 wrists in 14 patients with mild to moderate CTS. Using random allocation, group $A(n=8)$ received PSWD and group $B(n=8)$ received TENS twice a week for 6 consecutive weeks. Both groups also received exercise therapy and wrist orthoses. Assessments were done at baseline and at 6 weeks post intervention using Numeric Pain Rating Scale (NPRS) and Boston Carpal Tunnel Questionnaire (BCTQ) as outcome measures.

Results: Significant improvement in outcome measures were noted in group A (PSWD) compared to group B (TENS). The average baseline and final values of BCTQ measured in TENS group were 2.44 and 1.54, respectively, while the respective values for group PSWD were 2.69 and 1.36. The difference in BCTQ of patient who received PSWD and TENS were 1.33 and 0.9 respectively. The higher the difference between baseline and final values indicates better improvement in symptoms and function. NPRS was used to assess pain improvement. The average baseline and final values of NPRS in TENS group were 5.13 and 2.00, respectively. In PSWD group, the values were 5.38 and 0.75 , respectively. The outcome differences between both treatment groups were 3.13 in TENS group and 4.63 for PSWD group indicating good pain relief in the later group. 
Conclusion: Symptoms outcome, function and pain relief proved more efficacious in PSWD than TENS. Therefore, PSWD could be considered as a treatment option in mild to moderate CTS.

Keywords: Rehabilitation, Conservative Treatment, Peripheral Neuropathy, TENS 


\title{
Relation of Surgical Site Infection with Type of Femur Fracture Fixation: Cross-Sectional Study
}

\author{
SITI HAIARUL FA, NURUL SAKINAH WMA, CYNTHIA JOTHI R, \\ FATIN SURAINI M, SHAFIQ AIDI A, AHMAD FARIHAN MD \\ Department of Orthopaedics, Faculty of Medicine, Universiti Kebangsaan Malaysia \\ Medical Centre, Jalan Yaacob Latif, Bandar Tun Razak, 56000 Cheras, Kuala Lumpur, \\ Malaysia.
}

Background and aims: Surgical site infection (SSI) is a known complication following internal fixation of a femur fracture. It has a significant impact on patients as it prolongs hospital stay and increases medical expenses. The incidence of SSI may differ in various methods of internal fixation. This study was done to determine the incidence of SSI in patients who underwent open reduction and plating versus closed reduction and intra-medullary nail fixation in closed mid-shaft femoral fractures.

Materials and methods: A retrospective study was conducted in Universiti Kebangsaan Malaysia Medical Centre by identifying patients with closed mid-shaft femur fracture who underwent internal fixation surgery in between the year of 2010 to 2016. All patients had minimum follow-up of one year. This study was conducted via medical record tracing.

Results: A total 57 patients with mid-shaft femoral fracture underwent internal fixation surgery. There were 46 patients $(80.7 \%)$ who underwent intra-medullary nail fixation surgery, and 11 patients $(19.3 \%)$ underwent plate fixation surgery. The incidence of SSI was $9.1 \%$ for plate fixation and $2.2 \%$ for interlocking nail fixation. The calculated continuity correction for type of femoral shaft fixation with surgical site infection was $0.043(p=0.835)$.

Conclusion: There was no significant association between types of femoral shaft fixation with surgical site infection.

Keyword: Surgical Site Infection, Femur fracture, Internal fixation 


\title{
Normative Value of Maximum Phonation Time and Its Relation with Body Mass Index in Malaysia
}

\author{
NOOR ALIFAH AM' ${ }^{1}$, HAFFIZ HASLAM MA' ${ }^{1}$, KASTURI VK' ${ }^{1}$ NOR \\ ASYRAH MA ${ }^{1}$, MARINA MB ${ }^{1}$, NIK RITZA KNM ${ }^{2}$, NORLAILA \\ MUSTAFA $^{3}$
}

\begin{abstract}
${ }^{1}$ Department of Otorhinolaryngology, ${ }^{2}$ Department of Surgery, ${ }^{3}$ Department of Medicine, Faculty of Medicine, Universiti Kebangsaan Malaysia Medical Centre, Jalan Yaacob Latif, Bandar Tun Razak, 56000 Cheras, Kuala Lumpur, Malaysia.
\end{abstract}

Background and aims: Maximum Phonation Time (MPT) is a test to measure glottic efficiency for laryngeal pathology screening and treatment monitoring. To date, there is no normative value of MPT documented for South-East Asia population. Body Mass Index (BMI) may confound MPT. However, there is no strong evidence as yet. Therefore, this study aimed to establish the normative value of MPT and investigate the relationship with BMI.

Materials and Methods: This cross-sectional study was conducted in Universiti Kebangsaan Malaysia Medical Centre in 2017. Three hundred adult participants with normal voice were recruited; males and females were 150 respectively. BMI and Voice Handicap Index-10 (VHI-10) were recorded. Each gender was divided into three groups: non-obese $\left(n=50 ; B M l<22.9 \mathrm{~kg} / \mathrm{m}^{2}\right)$; obese $(n=50 ; B M I ~ 23-34.9$ $\left.\mathrm{kg} / \mathrm{m}^{2}\right)$; and morbidly obese $\left(\mathrm{n}=50 ; \mathrm{BMl}>35 \mathrm{~kg} / \mathrm{m}^{2}\right)$. Average of three readings of MPT was measured using stopwatch while the participants phonate ' $a$ ', ' $i$ ' and ' $u$ '. Unpaired t-test and ANOVA was used to compare means between and across groups. Spearman correlation assessed the correlation between MPT and BMI.

Results: Males and females with mean age of $30.35 \pm 10.52$ and $30.11 \pm 11.56$, respectively had normal voice with $\mathrm{VHI}-10$ of $1.00 \pm 2.62$. The normative value of MPT ('a') in non-obese group was of $21.41 \pm 6.85 \mathrm{~s}$ (male) and 18.05 $\pm 5.06 \mathrm{~s}$ (female). The MPT for each vowel across the groups was significantly higher in male $(p<0.05)$. In different BMI group of both genders, the mean MPT was also significantly different $(p<0.01)$. There was significant negative correlation between MPT and BMI $(-0.41<$ $r<-0.31)$ in both genders $(p<0.01)$.

Conclusion: This is the first study documented the normative value of MPT in Malaysian population in which the MPT was longer in male than female across the groups. Obesity may affect the ability to sustain the voice hence, the MPT reduced.

Keywords: Voice, Phonation, Obesity, Vocal Cord 


\title{
Development of Multilayer Scaffolds Using Electrospun Fibres and Hydrogel
}

\author{
NURUL AWATIF $\mathrm{H}$, KAVIYARASI SUBRAMANIAM, AIN FADILLA \\ A, NOR SUHAILAH S, SHARIL NAIM S, SHIPLU ROY C
}

Tissue Engineering Centre, Faculty of Medicine, Universiti Kebangsaan Malaysia Medical Centre, Jalan Yaacob Latif, Bandar Tun Razak, 56000 Cheras, Kuala Lumpur, Malaysia.

Background and aims: In tissue engineering, various 3D scaffolds are used to mimic the architecture of the target tissue. However, fabrication of complex structures such as a highly aligned 3D scaffold, which is desirable for muscle, tendon, ligament, neural tissue, is still challenging. Electrospinning is commonly used to fabricated nanofibers for aligned tissue, however, fails to produce thick scaffolds. Moreover, as the thickness of the scaffold increases, viability of the cells in the core reduces due to lack of nutrients and oxygen. Hence, in this study, we aimed to produce a $3 \mathrm{D}$ scaffold with the thickness of $2 \mathrm{~mm}$ using porous collagen and gelatin hydrogel and electrospun nanofibers for constructing aligned tissue substitutes.

Materials and methods: Acid soluble collagen type I was isolated from sheep tendon, and neutralized to $\mathrm{P}^{\mathrm{H}} 7.0$ to form hydrogel while incubated at $37^{\circ} \mathrm{C}$. In contrast, $10 \%$ gelatin solution was crosslinked with $0.1 \%$ genipin and incubate $4-5$ hours at $37^{\circ} \mathrm{C}$ for hydrogel formation. Poly Lactic-co-Glycolic Acid (PLGA) (20\%) was used to fabricate align nanofibre using electrospinning technique. Multilayer scaffolds were fabricated by stacking 1,2 and 3 layers of hydrogel alone, alternate layers of nanofiber and hydrogel and nanofibers alone. Finally, the viability of fibroblasts was assessed in the scaffolds.

Results: Tissue scaffolding using gelatin hydrogel showed a consistent polymerization process, scaffold handling, and timesaving as compared to collagen hydrogel. Scanning electron microscopy (SEM) of layered scaffolds showed intact nanofibres in between the hydrogel layers. The viability of the cells found to decrease with increasing number of layers, however, require the analysis of more samples to establish statistical significance.

Conclusion: A multilayer 3D scaffolds were successfully fabricated by integrating gelatin hydrogel and nanofiber mesh. Although, collagen was preferable for cellular functionality, however, further standardization of collagen isolation and hydrogel formation is required for consistent output.

Keywords: Gelatin, Hydrogel, Nanofiber, Alignments, Viability 


\title{
Is Statin Effective in Reducing Recurrence Rate of Post-Operative Chronic Subdural Hematoma?
}

\author{
ROYSTANCE KEANE YZ, ASHIQIN NORHISHAM, ANNE \\ MARGARET P, FATIMAHTUL ZAHRAA W, SANMUGARAJAH \\ PARAMASVARAN
}

Department of Surgery, Faculty of Medicine, Universiti Kebangsaan Malaysia Medical Centre, Jalan Yaacob Latif, Bandar Tun Razak, 56000 Cheras, Kuala Lumpur, Malaysia.

Background and aims: Statin has been known to have angiogenesis, neurogenesis, anti-oxidant and anti-inflammatory properties. The main aim of the study is to investigate the role of statin in reducing recurrence rate of post-operative chronic Subdural Hematoma (cSDH).

Materials and methods: In this retrospective study, a total of 71 cases from Universiti Kebangsaan Malaysia Medical Centre were collected using medical records to evaluate the role of statin in reducing recurrence rate of post-operative $\mathrm{CSDH}$. They were divided into statin and non-statin group. The diagnosis of recurrent $\mathrm{cSDH}$ patient was made by referring to the post-operative Computed Tomography (CT) imaging and the need for reoperation.

Results: Out of 33 cases that were included in the study, 8 cases were on statin therapy and 25 were not on statin therapy. Of 71 cases, 38 were excluded due to usage of anti-coagulant, death and defaulted follow-ups. Based on Chi-square test, there was no association between statin therapy and recurrence rate of postoperative $\mathrm{cSDH}$ as the result was not significant ( $p>0.05)$.

Conclusion: This study showed that statin does not help in reducing the recurrence rate of post-operative $\mathrm{cSDH}$. As a recommendation, a larger sample size is needed for further study.

Keywords : Statin, Hematoma, Craniotomy, Headache, Hypertension 


\title{
Sleep Assessment among Preclinical and Clinical Medical Students
}

\author{
FATIN AFIFAH R, ZUL AZLIN
}

Department of Psychiatry, Faculty of Medicine, Universiti Sains Islam Malaysia.

Background and aims: Good sleep quality is essential to university students especially among medical students as they need to retain substantial amount of knowledge. However, the quality of sleep among medical students have not been exclusively studied. The present study may aid in planning proper intervention for achieving good sleep quality among medical students. The aim of this research was to assess the sleep quality of Universiti Sains Islam Malaysia medical students and to determine the prevalence of poor sleep among them.

Materials and methods: The study comprised a total of 147 respondents including 75 preclinical students and 72 clinical students, $(M=45, F=102)$ recruited from Universiti Sains Islam Malaysia who completed Pittsburgh Sleep Quality Index (PSQI) questionnaire.

Results: The study showed that $56 \%$ preclinical students (mean PSQI global score $=5.08 \pm 2.28$ ) and $61.11 \%$ clinical students (mean PSQI global score=5.22 \pm 2.59 ) have poor sleep quality. Clinical students have reported having worse sleep than pre-clinical students. There was no significant gender differences in the sleep quality for both groups ( $p=0.872$ and $p=0.130$ respectively). This data is important in improving the overall quality of their life and academic performance. However, due to the limitation of time and resources, causes of poor sleep were not investigated.

Conclusion: In conclusion, the high prevalence of poor sleep among medical students is worrisome. Thus, suggestion for initiative to improve general sleep education for medical students, identify student at risk and target them with programs to improve sleep should be taken in consideration.

Keywords: Sleep Quality, Medical Student, Prevalence 


\title{
Finding the Rare Cells in Liver Cancer: Exploring the Potential of Prognostic and Predictive Biomarkers in Circulating Tumour Cells in Patients with Hepatocellular Carcinoma
}

\author{
RABBIAATUL ADDAWIYAH I, MISTI MC CAIN², HELEN REEVES², \\ DAVID JAMIESON ${ }^{2}$ \\ ${ }^{1}$ Newcastle University Medical School Malaysia. \\ ${ }^{2}$ Northern Institute for Cancer Research, Newcastle University UK.
}

Background and aims: When it comes to Hepatocellular Carcinoma (HCC), there's one burning question that is yet to be answered: What is the key driver mutation or the first defect point in cells to become cancerous for HCC? Unlike other types of cancer like breast cancer, which has a specific key driver mutation the exact point in HCC is still blurry. This is mainly because heterogeneity in every HCC mutations makes it difficult to find a common point in them. Hence, we are still unable to have one single universal biomarker that can detect every HCC. This research aimed to detect the presence of circulating tumour cells (CTCS) in HCC patients and quantify the prevalence of specific biomarkers which are DNA-PK (DNA dependent protein kinase), panCK (pan-Cytokeratin), FGFR4 (Fibroblast Growth Factor Receptor 4), c-Met (tyrosine-protein kinase Met) and pERK (Phosphorylated ERK) on these CTCs. The impact of knowing the most prevalent biomarker enables early detection for HCC, treatment stratification and as target for drug development and perhaps someday leads to the discovery of the universal biomarker for HCC?

Materials and methods: Patients blood samples first underwent red blood cell lysis. Then EasySep ${ }^{\mathrm{TM}}$ Human Whole Blood CD45 Depletion Kit was used to deplete the white blood cells in the samples. Next, antibody staining was done for each biomarker. Finally, samples were run through ImageStream ${ }^{\circledR}$ and analysed using the $\operatorname{IDEAS}^{\circledR}$ software.

Results: pan-CK and c-MET are two of the highest prevalent biomarker in the samples studied with $55.77 \%$ and $48.08 \%$ respectively. These were followed by negative biomarkers, DNA-pk and p-ERK.

Conclusion: pan-CK and C-Met biomarkers were found to have the highest prevalence in these samples. These two biomarkers should be focussed on for future studies on early detection of HCC and as target in drug development.

Keywords: Hepatocellular Carcinoma, Circulating Tumour Cells, Biomarkers 


\title{
Knowledge of and Willingness to Perform 'Hands- Only ${ }^{\mathrm{TM}}$ ' Cardiopulmonary Resuscitation among College Students in Malaysia
}

\author{
SUMITRA ROPINI K, PUTRI JASMINE FF, SHARMMATHEVAN \\ P, ALOHA DEE-AFRYNA GA, JIA XUAN C, CHRIS DOM S, \\ MONISHAK R
}

Department of Social and Preventive Medicine, Faculty of Medicine, University of Malaya, Kuala Lumpur, Malaysia.

Background and aims: Worldwide, millions of people die of sudden cardiac arrest every year. Both the layperson and healthcare providers are reluctant to perform out-of-hospital CPR due to the need for mouth-to-mouth contact. Hence, the Basic Life Support (BLS) algorithm has been simplified and lay rescuers are encouraged to perform Hands-Only ${ }^{\top M} C P R$. The study aimed to assess knowledge on and willingness to perform Hands-Only ${ }^{\top M} C P R$ among Malaysian college students and to determine the relationship between the two.

Materials and methods: An online self-administered questionnaire was used to collect data. Participants were asked closed-ended questions on their demographics, exposure to $\mathrm{CPR}$, knowledge of Hands-Only ${ }^{\mathrm{TM}} \mathrm{CPR}$, and their willingness to Perform Hands-Only ${ }^{\top M}$ CPR in 5 different scenarios (family members or relatives, stranger, trauma victim, child and elderly person). In the analysis, the independent sample t-test and One-way ANOVA procedure were used.

Results: Data for 393 participants were analysed. For knowledge, out of the maximum possible score of 14 , the mean score was $8.6 \pm 3.2$ and the median score was 9 . The distribution was fairly symmetrical. Majority of the respondents $(67.7 \%)$ were willing to perform Hands-Only ${ }^{\top M} C P R$ on their family members or relatives, but not as many were as willing to perform it in the other four scenarios. Majority of those who were not willing to perform Hands-Only ${ }^{\top M}$ CPR cited lack of knowledge as the main reason. Out of the $393,27 \%$ did not attend any CPR training before, three-quarter of them citing that they were unsure where to attend the course.

Conclusion: Knowledge on Hands-Only ${ }^{\top M} C P R$ among local college students is not encouraging. Higher knowledge is associated with previous training, however, not many know where to attend such courses. Those with better knowledge were found to be more willing to perform Hands-Only ${ }^{\top M}$ CPR.

Keywords: Hands-Only ${ }^{\top M} C P R$, Knowledge, Willingness 


\title{
Predicting the Recovery of Hypothalamic Pituitary Adrenal Axis After Prolonged Glucocorticoid Use
}

\author{
HOE LEONG S , SHUBASH SHANDER G , JEYAKANTHA R \\ Faculty of Medicine, University of Malaya, Kuala Lumpur, Malaysia. \\ Institute of Public Health, Ministry of Health, Kuala Lumpur, Malaysia. \\ Endocrine Unit, Department of Medicine, University Malaya Medical Centre, Kuala \\ Lumpur, Malaysia.
}

Background and aims: Prolonged exposure to glucocorticoids lead to hypothalamic-pituitary adrenal (HPA) axis suppression that recovers after cessation of treatment. This study aimed to identify the predictive factors for HPA axis recovery after prolonged glucocorticoid use.

Materials and methods: Retrospective review of patients who had undergone first short Synacthen test (SST) to assess HPA axis recovery after prolonged use of glucocorticoids at University of Malaya Medical Centre (UMMC) Endocrine Unit Day Care between January 2013 and December 2016. All data were obtained from Electronic Medical Record (EMR).

Results: A total of $47 \%$ (15/32) patients had adequate SST response at a median time of 2 years after diagnosis of adrenal insufficiency. Those who had inadequate response during SST had lower ambulatory early morning cortisol $(p<0.01)$ and higher final cumulative hydrocortisone dose $(p=0.01)$. Age, gender, body mass-index, type, route and duration of glucocorticoids used and basal adrenocorticotropic hormone (ACTH) levels were not predictive of HPA axis recovery. On multivariate analysis, the ambulatory early morning cortisol was the only independent predictor of adequate SST response, OR: 1.02, 95\% Cl: 1.01-1.04, $\mathrm{p}<0.01$. Using the receiveroperating characteristic curve (ROC), an ambulatory early morning cortisol of 243.5 $\mathrm{nmol} / \mathrm{L}$ predicted a positive SST response with a sensitivity of $75 \%$ and specificity of $94 \%$.

Conclusion: An early morning ambulatory cortisol could be used to decide on timely SST in order to prevent complications from unnecessary replacement with glucocorticoids.

Keywords: Adrenal Insufficiency, Adrenal, Hypopituitarism 


\title{
Traffic-Related Deaths - Twenty Years Forensic Autopsy Study
}

\author{
IIE WEN O, SU YING C, PRASHANT NARESH S, NURUL \\ SYUHADA R \\ Department of Forensic Pathology, Faculty of Medicine, University Malaya Medical \\ Centre.
}

Background and aims: Road transportation accidents were important causes of morbidity and mortality. This was predominantly due to increase in number of vehicles, change in lifestyle and behaviour pattern amongst general population. This research aimed to study the epidemiology of traffic-related deaths and discuss on the comparative study with age group, gender, ethnicity, district and types of fatal injuries.

Materials and methods: A retrospective autopsy-based study was conducted in Department of Forensic Pathology, University Malaya Medical Centre. After reviewing the cases encountered, a literature search of 10167 cases of autopsies conducted over past two (2) decades (1996-2015) revealed 2696 (27\%) deaths associated to traffic incident.

Results: Majority of deaths were noted in the year 1996 (204), followed by 2003 (197). Significant fatalities were found amongst young adults with an age group 21-30 years amounting to $36.4 \%$ of total loss. The gender differentiation affected predominantly the male $(85.5 \%)$ population with a ration of 5.97:1. For adults, Malays $(41 \%)$ were affected predominantly followed by Chinese $(22.4 \%)$ and Indians (20.5\%). The most concerning age groups were the teenage, the second and third decades. Multiple injuries were noted as the cause of death in $42.8 \%$ fatalities, followed by traumatic head injury $(40.1 \%)$. Traffic related deaths were found to peak in March, June and October months, which coincided with the wet weather subjected to monsoon in Kuala Lumpur.

Conclusion: It was apt to conclude that road traffic accidents were important preventable public health hazards and should be addressed by strengthening of traffic regulations, safe driving policies and defensive driving traffic education on a regular basis.

Keywords: Traffic Accidents, Multiple Injuries, Traumatic Head Injuries 


\title{
Cross-Sectional Survey on Zika Virus Awareness among Students of the National Defence University of Malaysia
}

\author{
CHRISENDER DEVADASON F, ASWINKUMAR GUNASEGARAN, \\ CHIENG DIH C, LEEYNESH SOORIYAPIRAGASAM \\ Community Medicine Unit, Faculty of Medicine and Defence Health, National Defence \\ University of Malaysia.
}

Background and aims: Since 2015, the Zika virus (ZIKV) has had an impact on the world in recent times, causing a worldwide health alert in major countries such as Malaysia. There is a potential of ZIKV re-emergence in Malaysia due to high density of its vectors, thus public awareness about ZIKV is important. The present study aimed to assess ZIKV knowledge, attitudes and practices (KAP) among students of the National Defence University of Malaysia (NDUM).

Materials and methods: A cross-sectional survey was conducted in April 2017. A total of 126 students from NDUM were recruited by stratified sampling method. Data were collected via self-administered pre-tested structured questionnaires and analysed descriptively. Cut-off of achieving more than $75 \%$ of the total score was used for good level of KAP. To explore the factors associated with the level of ZIKV $\mathrm{KAP}$, chi-square test was applied.

Results: The participants had moderate knowledge (15.3 \pm 4.6$)$, attitudes $(26.2 \pm 3.3)$ and preventive practices $(4.0 \pm 1.7)$ towards ZIKV. Most of respondents had misconceptions about vector biting habits $(74 \%)$, possibility of developing neurological disorders (69\%) and risk of miscarriage in pregnancy $(58 \%)$. More than one-third (38.1\%) reported that women should avoid getting pregnant because of ZIKV, and more than half (55.5\%) did not believe that doctors could effectively treat the infection. Only one-third $(28.6 \%)$ reported that they check the toilet tank for mosquito larvae. Television (50\%) and Internet (41.3\%) were reported as the main sources of information about ZIKV. Attitudes towards ZIKV were statistically significantly $(p=0.031)$ more positive among year 3 students $(62.5 \%)$ compared to year 1 students (20.8\%).

Conclusion: This study identified gaps in the knowledge, attitudes and practices of university students towards ZIKV. Educational campaigns should be revised to address these gaps.

Keywords: Knowledge, Attitudes, Practices, Zika virus 